\title{
Little Helpers or Mean Rogue-Role of Microglia in Animal Models of Amyotrophic Lateral Sclerosis
}

\author{
Hilal Cihankaya ${ }^{1,2}$, Carsten Theiss ${ }^{1,2}$ (D) and Veronika Matschke ${ }^{1, *(\mathbb{D})}$ \\ 1 Department of Cytology, Institute of Anatomy, Ruhr-University Bochum, D-44801 Bochum, Germany; \\ hilalcihankaya@gmail.com (H.C.); carsten.theiss@rub.de (C.T.) \\ 2 International Graduate School of Neuroscience (IGSN), Ruhr-University Bochum, D-44801 Bochum, Germany \\ * Correspondence: veronika.matschke@rub.de; Tel.: +49-234-32-25018
}

check for

updates

Citation: Cihankaya, H.; Theiss, C. Matschke, V. Little Helpers or Mean Rogue-Role of Microglia in Animal Models of Amyotrophic Lateral Sclerosis. Int. J. Mol. Sci. 2021, 22, 993. https://doi.org/10.3390/ijms22030993

Academic Editor: Jacopo Meldolesi Received: 16 December 2020

Accepted: 16 January 2021

Published: 20 January 202

Publisher's Note: MDPI stays neutral with regard to jurisdictional claims in published maps and institutional affiliations.

Copyright: (c) 2021 by the authors. Licensee MDPI, Basel, Switzerland This article is an open access article distributed under the terms and conditions of the Creative Commons Attribution (CC BY) license (https:// creativecommons.org/licenses/by/ $4.0 /)$.

\begin{abstract}
Amyotrophic lateral sclerosis (ALS) is one of the most common neurodegenerative diseases, causing degeneration of both upper and lower motor neurons in the central nervous system (CNS). ALS patients suffer from hyperreflexia, spasticity, paralysis and muscle atrophy and typically die due to respiratory failure 1-5 years after disease onset. In addition to the degeneration of motor neurons on the cellular level, ALS has been associated with neuroinflammation, such as microgliosis. Microglial activation in ALS can either be protective or degenerative to the neurons. Among others, mutations in superoxide dismutase 1 (SOD1), chromosome 9 open reading frame 72 (C9Orf72), transactive response DNA binding protein (TDP) 43 and vacuolar protein sorting-associated protein 54 (VPS54) genes have been associated with ALS. Here, we describe the dual role and functionality of microglia in four different in vivo ALS models and search for the lowest common denominator with respect to the role of microglia in the highly heterogeneous disease of ALS.
\end{abstract}

Keywords: ALS; microglial activation; neuroinflammation; superoxide dismutase 1; chromosome 9 open reading frame 72; transactive response DNA binding protein 43; wobbler mouse

\section{Introduction}

Amyotrophic lateral sclerosis (ALS) is a fatal neurodegenerative disease which is characterized by rapid progressive degeneration of the upper motor neurons in the motor cortex and the lower motor neurons in the spinal cord and brain stem. The incidence of ALS is $2 / 100,000$ in Europe, and older men are mostly affected, rather than women [1]. The most common form of ALS, seen in $90-95 \%$ of patients, is called sporadic ALS (sALS). To date, no genetic factors have been identified as being related to sALS. The second form of the disease is familial ALS (fALS), which is present only in $5-10 \%$ of the patients. Among others, mutations in superoxide dismutase 1 (SOD1), chromosome 9 open reading frame 72 (C9Orf72), transactive response DNA binding protein (TDP) 43 and fused in sarcoma (FUS) genes have been associated mostly with fALS [2]. Thirdly, there is a very rare form of ALS, known as juvenile ALS (jALS). ALS patients suffer from hyperreflexia, spasticity, paralysis, muscle weakness and muscle atrophy [3]. This progressive disease causes death due to respiratory failure 1-5 years after the onset of disease symptoms [3]. On the cellular level, ALS has been associated with motor neuron degeneration, neuroinflammation, increased oxidative stress, mitochondrial dysfunction, protein aggregation, impaired RNA processing, as well as impaired axonal transport [1]. A growing body of evidence suggests that not only motor neurons, but also glial cells like microglia are involved in ALS pathogenesis [4].

Microglia are the resident immune cells, and they comprise approximately $20 \%$ of the glial cell population in the central nervous system (CNS) [5]. Resting microglia have ramified morphology to survey the danger signals in the CNS parenchyma. Quiescent microglia transform into an amoeboid phenotype to become activated upon CNS diseases, injuries or pathogens. The morphology of microglia can be studied using specific markers, such as ionized calcium binding adaptor protein 1 (IBA1) or cluster of differentiation 11b 
molecule (CD11b) independently of their activation status. For example, IBA1, one of the microglia/macrophage markers and a calcium-binding protein [6], is well-studied in ALS animal models to demonstrate the cellular morphology of microglia and microgliosis, depending on the number and/or size of the IBA1 stained cells in the tissue. CD11b is an alpha integrin, which combines with CD18 to form a microglia/macrophage receptor on the cell membrane and plays a role in cell adhesion, migration, phagocytosis and survival at the inflammation site [7]. Additionally, other clusters of differentiation molecules are also utilized to characterize the microglia such as CD36 and CD68, which are activated by toll-like receptor (TLR) signaling [8,9], and CD40, which is required for microglia activation [10].

The morphology of microglia in ALS animal models varies depending on genetic background and the investigated region of the CNS (Table 1). It should be mentioned that both symptomatic and non-symptomatic animals of different models show predominantly amoeboid, and thus activated, microglia in the spinal cord and motor cortex.

Table 1. Morphology of microglia in the different amyotrophic lateral sclerosis (ALS) animal models based on genetic background, age, strain, collected tissue and microglial markers.

\begin{tabular}{|c|c|c|c|c|c|c|}
\hline Model & Strain & Age & Tissue & Microglial Marker & Morphology & Reference \\
\hline$S O D 1^{G 93 A}$ mouse & B6SJL-Tg & 4-6 weeks & spinal cord & IBA1, CD11b & ND & [11] \\
\hline$S O D 1^{G 93 A}$ mouse & B6SJL-Tg & 9 and 14 weeks & spinal cord & IBA1 & ND & [12] \\
\hline$S O D 1^{\mathrm{G} 93 A}$ mouse & B6SJL-Tg & 10 and 14 weeks & spinal cord & IBA1 & ND & [13] \\
\hline$S O D 1^{G 93 A}$ mouse & B6SJL-Tg & 12-14 weeks & spinal cord & IBA1, CD11b & Activated & [11] \\
\hline$S O D 1^{G 93 A}$ mouse & B6SJL-Tg & 14 and 20 weeks & spinal cord & IBA1 & ND & [14] \\
\hline$S O D 1^{G 93 A}$ mouse & B6SJL-Tg & 16 and 19 weeks & $\begin{array}{l}\text { medial reticular } \\
\text { formation }\end{array}$ & IBA1, CD68 & Amoeboid & [15] \\
\hline$S O D 1^{\mathrm{G} 93 A}$ mouse & B6SJL-Tg & 16-17 weeks & spinal cord & CD11b & ND & [16] \\
\hline$S O D 1^{G 93 A}$ mouse & B6SJL-Tg & 17 weeks & $\begin{array}{l}\text { retina, olfactory } \\
\text { bulb }\end{array}$ & IBA1 & Ramified & [17] \\
\hline$S O D 1^{G 93 A}$ mouse & B6SJL-Tg & 18 weeks & spinal cord & IBA1 & ND & [18] \\
\hline$S O D 1^{\mathrm{G} 93 A}$ mouse & B6SJL-Tg & NM & spinal cord & IBA1 & Activated & [19] \\
\hline$S O D 1^{\mathrm{G} 93 A}$ mouse & B6SJL-Tg & NM & spinal cord & CD11b & ND & [20] \\
\hline$S O D 1^{\mathrm{G} 93 A}$ mouse & B6. $\mathrm{Cg}-\mathrm{Tg}$ & 15 weeks & spinal cord & IBA1, CD40 & Activated & [21] \\
\hline$S O D 1^{G 93 A}$ mouse & B6.Cg-Tg & 16 weeks & spinal cord & IBA1, CD36 & Activated & [22] \\
\hline$S O D 1^{\mathrm{G} 93 A}$ mouse & B6. Cg-Tg & 16 weeks & spinal cord & IBA1 & ND & [23] \\
\hline$S O D 1^{\mathrm{G} 93 A}$ mouse & B6. $\mathrm{Cg}-\mathrm{Tg}$ & 17 weeks & spinal cord & IBA1, CD68 & ND & [24] \\
\hline$S O D 1^{G 93 A}$ mouse & B6. $\mathrm{Cg}-\mathrm{Tg}$ & 22 weeks & spinal cord & IBA1 & ND & [25] \\
\hline$S O D 1^{G 93 A}$ mouse & B6J-Tg & 16 weeks & $\begin{array}{l}\text { motor cortex } \\
\text { spinal cord }\end{array}$ & IBA1 & ND & [26] \\
\hline$S O D 1^{G 86 R}$ mouse & $\mathrm{FVB} / \mathrm{N}$ & NM & spinal cord & IBA1 & Activated & [27] \\
\hline$S O D 1^{G 93 A}$ mouse & NM & 15 weeks & spinal cord & IBA1, CD11b & ND & [28] \\
\hline$S O D 1^{G 93 A}$ mouse & NM & 14 weeks & spinal cord & IBA1 & ND & [29] \\
\hline$S O D 1^{G 93 A}$ mouse & $\mathrm{NM}$ & 18 weeks & spinal cord & IBA1 & Activated & [30] \\
\hline Poly-GA mouse & C57BL/6N-Tg & 3 weeks & hippocampus & IBA1 & Amoeboid & [31] \\
\hline Poly-GA-CFP mouse & C57BL/6N-Tg & 26 weeks & spinal cord & IBA1, CD68 & Phagocytic & [32] \\
\hline Poly-GA mouse & C57BL/6J-Tg & 28 weeks & spinal cord & IBA1 & Activated & [33] \\
\hline Poly-PR mouse & C57BL/6N-Tg & 4 and 68 weeks & hippocampus & IBA1 & Ramified & [31] \\
\hline GFP-(GR) $)_{100}$ & C57BL/6J & 6 weeks & brain & IBA1 & ND & {$[34]$} \\
\hline$T D P-43^{Q 331 K}$ mouse & C57BL/6J-Tg & 10 and 16 months & spinal cord & IBA1 & Amoeboid & [35] \\
\hline$T D P-43^{Q 331 K}$ mouse & C57BL/6J-Tg & 16 months & spinal cord & CD11b & Amoeboid & [35] \\
\hline
\end{tabular}


Table 1. Cont.

\begin{tabular}{|c|c|c|c|c|c|c|}
\hline Model & Strain & Age & Tissue & Microglial Marker & Morphology & Reference \\
\hline $\begin{array}{c}\text { prpTDP-43 }{ }^{A 315 T} \\
\text { UCHL1eGFP mouse }\end{array}$ & C57BL/6-Tg & 3,4 and 5 months & motor cortex & IBA1 & Activated & {$[36]$} \\
\hline$T D P-43^{A 315 T}$ mouse & C57BL $/ 6$ x CBA-Tg & 4.5 months & spinal cord & $\mathrm{CD} 11 \mathrm{~b}$ & ND & [37] \\
\hline$W r$ mouse & C57BL/6J-wr & $\mathrm{P} 20, \mathrm{P} 40$ and P60 & $\begin{array}{l}\text { motor cortex, } \\
\text { cerebellum }\end{array}$ & IBA1 & ND & {$[38,39]$} \\
\hline$W r$ mouse & NFR-wr & P28 & spinal cord & $\mathrm{CD} 11 \mathrm{~b}$ & $\begin{array}{l}\text { Ramified and } \\
\text { clusters }\end{array}$ & {$[40]$} \\
\hline$W r$ mouse & NFR-wr & $\mathrm{P} 42$ & spinal cord & $\mathrm{CD} 11 \mathrm{~b}$ & $\begin{array}{c}\text { Ramified and } \\
\text { amoeboid }\end{array}$ & [41] \\
\hline$W r$ mouse & NFR-wr & P60 & spinal cord & IBA1 & Highly reactive & [42] \\
\hline$W r$ mouse & NFR-wr & P60 & spinal cord & CD11b & ND & [42] \\
\hline$W r$ mouse & NFR-wr & P63 & spinal cord & CD11b & Activated & [40] \\
\hline Wr mouse & NFR-wr & P70 & spinal cord & CD11b & ND & [43] \\
\hline$W r$ mouse & NFR-wr & P84 & spinal cord & CD11b & ND & [44] \\
\hline$W r$ mouse & NFR-wr & P90 & dentate gyrus & IBA1 & Amoeboid & [45] \\
\hline$W r$ mouse & NFR-wr & $\mathrm{P} 150$ & spinal cord & IBA1 & ND & {$[46,47]$} \\
\hline$W r$ mouse & NFR-wr & P150 & spinal cord & IBA1 & Highly ramified & [48] \\
\hline$W r$ mouse & NFR-wr & P150 & spinal cord & CD11b & ND & [46-48] \\
\hline
\end{tabular}

Wr: Wobbler; $\mathrm{P}$ (number): postnatal days; IBA1: ionized calcium binding adaptor molecule 1; CD: cluster of differentiation molecule; ND: not described; NM: not mentioned.

Nowadays, it is known that the functional differentiation of microglia based on expression patterns, phenotype, and stimulus is far more complex than the concept of "classically activated" M1 and "alternatively activated" M2 polarization of microglia (Figure 1) [49]. In this review, we make use of this oversimplified microglial classification, since most studies in the field of ALS still use this categorization. M1-type microglia have been shown to contribute to motor neuron degeneration in ALS by releasing proinflammatory cytokines such as tumor necrosis factor alpha (TNF $\alpha$ ), interleukin 1 beta (IL-1 $\beta)$, interferon gamma (IFN- $\gamma$ ) and chemokines such as reactive oxygen species (ROS) and nitric oxide synthase (NOS) to initiate the immune response [4,50]. On the other hand, M2-type microglia can enhance the motor neuron survival in ALS by releasing anti-inflammatory cytokines such as transforming growth factor beta (TGF $\beta$ ), interleukin 4 (IL-4), interleukin 10 (IL-10), interleukin 13 (IL-13) and neurotrophins such as insulin-like growth factor (IGF-1) and brain-derived neurotrophic factor (BDNF) to repair and restore the damaged tissue [4,50].

Therefore, it is assumed that activated microglia play a dual role during the pathogenesis of ALS. It was hypothesized that M2-type microglia could be protective for the motor neurons during the early stage of ALS. However, as the disease progresses, a shift from neuroprotection to neurotoxicity has been noted, where M1-type microglia induce neuroinflammation and motor neuron degeneration at the later stages of ALS [51]. Thus, neuroinflammatory processes such as microgliosis seem to play a major role in the ALS pathology [52-54].

More recently, together with the identification of ALS-linked genes, the number of mouse models for ALS created by genetic engineering methods has increased significantly. Thus, various models are now available for the investigation of the pathological mechanisms in ALS. These mouse models show microgliosis in CNS tissue, similarly to ALS patients. It was demonstrated that proinflammatory and anti-inflammatory molecules are released by M1- and/or M2-type microglia, leading to modulation of the microglial activation states in ALS [55-57]. In various animal models of ALS, the application of different compounds has been able to improve the survival of motor neurons. Thereby, different targets of ALS pathology have been addressed, such as hyperexcitability and excitotoxicity, neuroinflammation and oxidative stress. Two compounds, riluzole and edaravone, which 
reduce excitotoxicity and oxidative stress, respectively, have already been approved for ALS patients, but with only moderate success. Other agents that interfere with immune response mechanisms and thus target neuroinflammation, such as TLR-4 inhibitors, H1receptor agonists and glucocorticoid receptor modulators, also showed a positive outcome on motor neuron survival in ALS animal models. Nevertheless, they remained rather unsuccessful after translation into clinical trials [58]. Reasons for failure could include the following: (i) preclinical studies have mostly been performed in only one ALS animal model, so the strong heterogeneity of the causes of the disease in different ALS cohorts would not be taken into account; (ii) an appropriate time window for the successful use of agents cannot be maintained in human patients [58]. The heterogeneity of the disease's etiology thus requires a target that addresses as many patient groups as possible. We thus compare in this review the behavior, properties and functions of microglia in the different animal models to get closer to the goal of a common target.

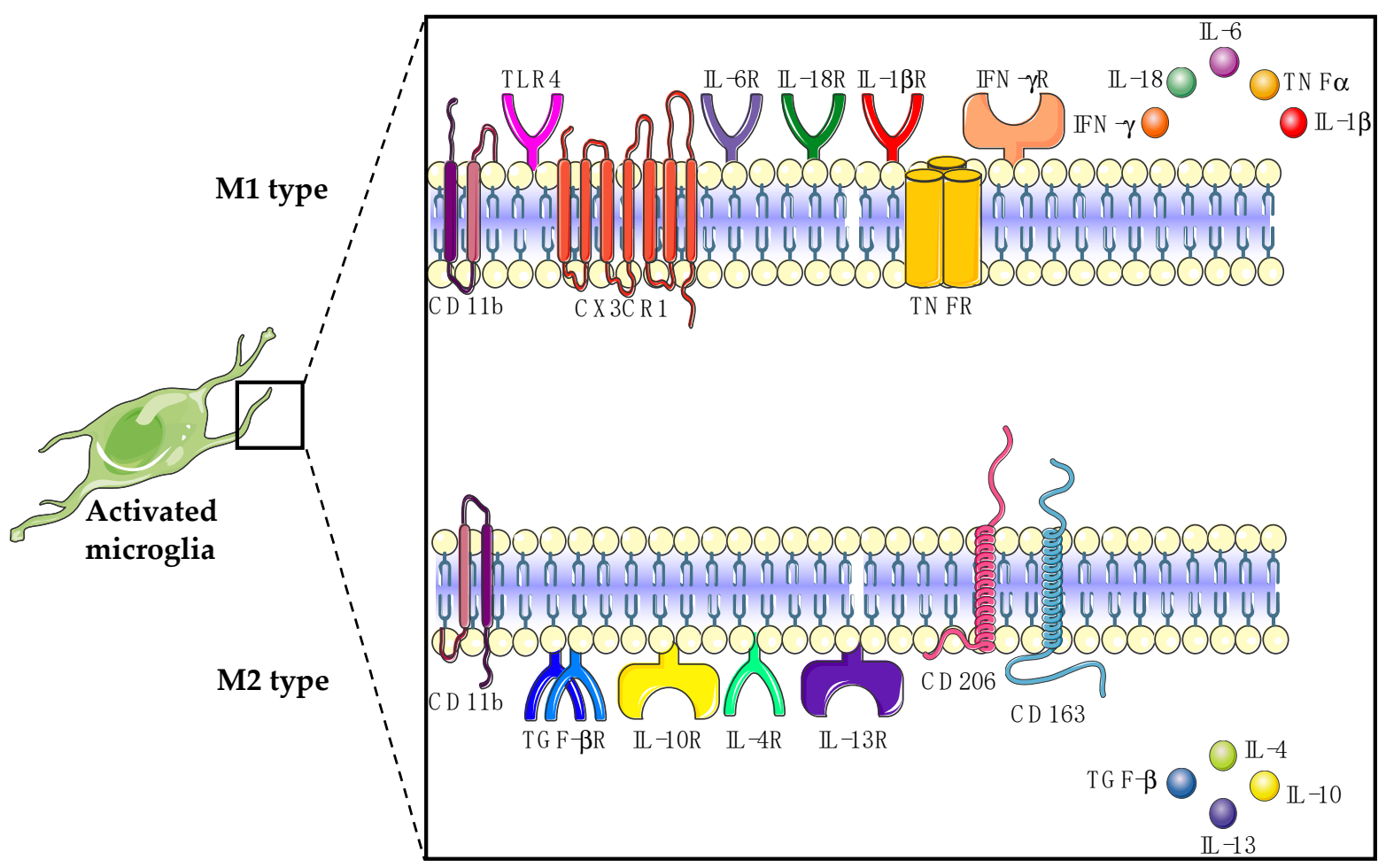

Figure 1. Classically activated M1-type microglia release proinflammatory cytokines, whereas alternatively activated M2-type microglia release anti-inflammatory cytokines. CD: cluster of differentiation; CX3CR1: C-X3-C motif chemokine receptor 1; TNF $\alpha$ : tumor necrosis factor alpha; TNFR: TNF $\alpha$ receptor; IFN- $\gamma$ : interferon gamma; IFN- $\gamma$ R: IFN- $\gamma$ receptor; TLR4: toll-like receptor 4; IL: interleukin; TGF $\beta$ : transforming growth factor beta; TGF $\beta$ R: TGF $\beta$ receptor.

\section{SOD1 Model}

About 25 years ago, the first gene mutation in the human superoxide dismutase (SOD) 1 gene was linked to the disease of ALS [59]. However, in Europe only 15\% of fALS and 1-2\% of sALS cases have been associated with mutations in the SOD1 gene [60]. SOD1 encodes an enzyme responsible for the detoxification of free superoxide radicals by converting them to hydrogen peroxide and molecular oxygen. However, a mutated allele can acquire both gain-of-function and loss-of-function mutations. It is currently assumed that toxic gain-of-function mutations in the SOD1 gene generate mutation-induced misfolding of SOD1 and subsequent SOD1 aggregation [61]. This results in increased oxidative activity, leading to redundant production of hydrogen peroxide and molecular oxygen, together with an increased number of protein-protein interactions [62]. These days, more than 
170 mutations have been described in human ALS cases (http:/ /www.hgmd.org, accessed in January 2021) and numerous SOD1 animal models have been developed. Based on the genetic background, the type of mutation and the copy number of the mutated SOD1 allele, animals can vary in showing ALS symptoms with different progression rates [63-66]. In the case of the most studied mutation - that causing a glycine-to-alanine change at the 93rd codon (G93A) in the SOD1 gene-animals carrying mutant alleles, depending on the genetic background, have a range of survival of 17 to 26 weeks, and the disease onset starts about the 13th-17th weeks of age, when animals start to develop hind limb weakness $[63,64,66-68]$. One to two months after the disease onset, which is also called the symptomatic stage, $S O D 1^{G 93 A}$ mice begin to show tremors, locomotor deficits, paralysis, mitochondrial vacuolization, neurofilament aggregations, gliosis and degeneration of axons and motor neurons [67]. This ALS model, as well as models with other SOD1 mutations underlying ALS, shows microglial changes predominantly in the disease onset and symptomatic phase in different regions of the CNS, as summarized in the following paragraphs and in Table 2.

\subsection{Microglial Morphology of the SOD1 Models}

It is known that $S O D 1^{G 93 A}$ mice show increased microgliosis, as a significant increase in IBA1 in Western blot analysis was found in the spinal cords of the pre-symptomatic and symptomatic $S O D 1^{G 93 A}$ mice [11]. Medial reticular formation of $S O D 1^{G 93 A}$ mice showed IBA1+ activated microglia, which were found in close proximity to Chx10+ glutamatergic V2a neurons [15]. In 10- and 14-week-old $S O D 1^{\mathrm{G} 93 A}$ mice, mRNA expression of $I b a 1$ was increased in the spinal cord when compared to WT-SOD1 mice ${ }^{13}$. A total of $96 \%$ of the IBA1 signal from the spinal cord of SOD1 ${ }^{G 93 A}$ mice showed colocalization with keratan sulfate marker 5D4 [69]. There were no significant changes observed between wild-type and end-stage $S O D 1^{G 93 A}$ mice in terms of the number of IBA1+ microglia taken from the external plexiform layer of the olfactory bulb and the internal plexiform layer of the retina [17]. The numerical density of IBA1+ and pSTAT3+/IBA1+ microglia gradually increased from 9 weeks to 21 weeks of age in the ventral spinal cords of SOD $1^{\mathrm{G} 93 \mathrm{~A}}$ mice and most of the pSTAT3+/IBA1+ microglia were also positive for proinflammatory microglial markers Kv1.3 and Kv1.5 in 21-week-old $S O D 1^{G 93 A}$ mice [70]. The increased number of IBA1+ cells were reduced in the cervical spinal cord and in the motor cortex of transgenic Klotho-overexpressing 16-week-old SOD1 ${ }^{G 93 A}$ mice (Klotho is an anti-inflammatory, antioxidative, neuroprotective and promyelinating protein.) [26]. Ubiquitin-positive aggregations surrounded by IBA1+ microglia were observed in both

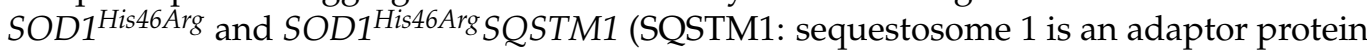
regulating autophagy and anti-oxidative stress pathway) mice; however, there were no statistical differences between these groups [71]. Iba1 and CD68 mRNA levels remained unchanged, when NOX2 was knocked-out in $S O D 1^{G 93 A}$ mice [19]. Broad spectrum NOX inhibitor perphenazine treatment of $S O D 1^{G 93 A}$ mice increased $I b a 1$ and $C D 68$, whereas administration of another NOX inhibitor, thioridazine, resulted in a significant decrease of $I b a 1$ and $C D 68$ in the spinal cord of $S O D 1^{G 93 A}$ mice [19]. Ablation of serotonin $2 \mathrm{~B}$ receptor $\left(5-\mathrm{HT}_{2 \mathrm{~b}}\right)$ in $S O D 1^{\mathrm{G} 86 R}$ mice resulted in a reduced IBA1 immunoreactivity in the spinal cord, where almost $50 \%$ of IBA1+ cells displayed cytoplasmic fragmentation [27].

In detail, both female and male SOD ${ }^{\text {G93A }}$ mice showed increased IBA+ immunostaining in the ventral horn when compared to WT litters; however, long term interleukin 33 (IL-33) treatment of $S O D 1^{\mathrm{G} 93 A}$ mice failed to alter microgliosis in either gender [25]. IBA1 quantification of tempol (a cyclic nitroxide)-injected SOD1 ${ }^{\text {G93A }}$ mice at 14 weeks (early symptomatic phase) showed less microglial activation in the ventral horn of the spinal cord, and tempol-injected $S O D 1^{G 93 A}$ mice at 20 weeks (end stage) revealed a significant reduction in the microglial activity in the ventral, intermediate and dorsal regions of the spinal cord, when compared to the vehicle and riluzole-treated groups, respectively [14]. In different studies, Gamisoyo-San (a herbal medicine), TRAM-34 (selective $\mathrm{Ca}^{2+}$ activated $\mathrm{K}^{+}$channel KCa3.1 inhibitor), TAK-242 (exogenous synthetic selective inhibitor of TLR4) 
and $\mathrm{KCHO}-1$ (a herbal combination compound containing 30\% ethanol and nine different herbal extracts) administration to $S O D 1^{G 93 A}$ mice attenuated the IBA1 expression in the spinal cord $[18,23,28,29]$. A tyrosine kinase inhibitor (masitinib) treatment of postparalyzed $S O D 1^{G 93 A}$ rats ameliorated the microgliosis in the ventral spinal cord, as shown by IBA1 immunostaining [72]. Infusion of 15-week-old $S O D 1^{\mathrm{G} 93 A}$ brains with antisense oligonucleotide against cytosolic phospholipase $\mathrm{A}_{2}$ alpha $\left(\mathrm{CPLA}_{2} \alpha\right)$ inhibited the microglial activation in the spinal cord sections, as detected by IBA1 and CD40 immunostaining [21]. Immunohistochemical staining of AMD3100 (an inhibitor of CXCL12 binding to CXCR4)treated $S O D 1^{G 93 A}$ mice revealed significantly reduced IBA1 and CD36 levels in the spinal cord [22].

Rather than IBA1, CD11b has also been used in studies to investigate microgliosis and the general morphology of the microglia. Symptomatic 22-24-week-old NLRP3-GFP$S O D 1^{\text {G93A }}$ mice demonstrated NLRP3-GFP colocalization with CD11b in the ventral lumbar spinal cord [73]. Brain-derived extracellular micro-vesicles (BDEVs) from 2- and 5-monthold SOD $1^{\mathrm{G} 93 A}$ mice revealed less than $5 \% \mathrm{CD} 11 \mathrm{~b}+$ vesicles in the flow cytometry analysis, indicating the absence of microglial markers in these BDEVs [74]. Although surprisingly decreased $C D 11 b$ mRNA was detected in the spinal cord of the pre-symptomatic $S O D 1^{G 93 A}$ mice, a significant increase was seen in the $C D 11 b$ levels in the symptomatic $S O D 1^{G 93 A}$ mice [11]. CD11b expression was significantly decreased in the spinal cord of the $S O D 1^{\mathrm{G} 93 A} \mathrm{Grm5}^{+/-}$mice, when compared to SOD1 ${ }^{\mathrm{G} 93 A}$ mice (Grm5: mGluR5 inactivating mutation) [16]. Gamisoyo-San (GSS) treatment of $S O D 1^{G 93 A}$ mice reduced the CD11b expression in the spinal cord [28]. Treatment of $S O D 1^{G 93 A}$ mice with IL-2c reduced CD11b immunoreactivity by $50 \%$ in spinal cord sections [20]. $S O D 1^{\mathrm{G} 93 A}$ mice that were either forced to exercise or treated with nandrolone (an anabolic androgenic steroid) in addition to physical exercise showed enhanced CD11b immune reactivity in the ventral horn of the lumbar spinal cord [75].

\subsection{Microglial Markers in the SOD1 Models}

Proinflammatory factors have been intensively investigated in several SOD1 models due to their cytotoxic effects on motor neuron degeneration. TLR2, TLR4, nuclear factor kappa B (NFKB) and high mobility group box protein 1 (HMGB1) protein levels remained unaltered in the spinal cord of the pre-symptomatic $S O D 1^{\mathrm{G} 93 \mathrm{~A}}$ mice; however, protein levels of TLR2 and TLR4 were decreased, together with an increase in the HMBG1, NFKB and phosphorylated NFKB levels in the spinal cord of the symptomatic SOD1 ${ }^{\mathrm{G} 93 \mathrm{~A}}$ mice [11]. mRNAs of M1-type markers MhcII, Cebpa and CD80 remained unchanged in the pre-symptomatic $S O D 1^{G 93 A}$ mice; however, they were significantly increased in the symptomatic SOD1 ${ }^{\mathrm{G} 93 A}$ mice [11]. CX3CR1, the only receptor of chemokine (C-X-C motif) ligand 1 (CX3CL1), was found to be located mainly in the microglia of $S O D 1^{\mathrm{G} 93 A}$ mice, as shown by IBA1 and CX3CR1 double immunofluorescent staining [76]. In the same study, the number of CD86+/IBA1+ microglia was significantly increased in the anterior horn of SOD1 ${ }^{\mathrm{G} 93 A}$ mice at P90 and P120 [76]. Concordantly, M1-type markers iNOS and CD86, together with M1-type cytokines Il-1 $\beta$ and Tnf $\alpha$, were increased at the mRNA level in P90 and P120 SOD1 ${ }^{\text {G93A }}$ mice [76]. HuR, an RNA binding protein, colocalized with IBA1 in the cytoplasm of activated microglia in spinal cord of 18-week-old mutant SOD1 mice [30]. Arylsulfatase B (ARSB) was found to be partially expressed by microglial cells in both wild-type and $S O D 1^{\mathrm{G} 93 A}$ mice [77]. Ablation of serotonin $2 \mathrm{~B}$ receptor $\left(5-\mathrm{HT}_{2 \mathrm{~b}}\right)$ in $\mathrm{SOD} 1^{\mathrm{G} 86 R}$ mice resulted in reduced mRNA levels of Nox2, Ccl4 and MhcII in the brain stem [27].

Nucleotide binding domain and leucine rich repeat containing protein 3 (NLRP3) inflammasome is an intracellular multiprotein complex that can activate the innate immune system upon interaction with foreign molecules. This activation can trigger neuroinflammation, as observed in animal ALS models and ALS patients [73]. mRNA expressions of Il-1 $\beta$, Nlrp3, Asc and Caspase-1 were upregulated in the spinal cord samples of 22-24-week-old SOD1 ${ }^{\text {G93A }}$ mice [73]. Nlrp3, Il-1 $\beta$, Il-6 and Tnfo mRNAs were downregulated in pre-symptomatic SOD1 ${ }^{\mathrm{G} 93 A}$ mice; however, Nlrp3, Il-1 $\beta, I l-10$ and Tnf $\alpha$ mRNAs 
were upregulated in symptomatic SOD $1^{\text {G93A }}$ mice [11]. Nlrp3 and Il-1 $\beta$ mRNA expressions were induced in both 9-week-old and 14-week-old SOD1 ${ }^{\text {G93A }}$ mice, whereas Asc and Il-18 mRNA expressions remained unchanged among wild-type and $S O D 1^{G 93 A}$ groups [12]. Protein levels of ASC, NLRP3, IL-1 $\beta$, IL-18 and active caspase 1 were found to be increased in SOD1 ${ }^{\mathrm{G} 93 A}$ mice [12]. IBA1+ cells did not colocalized with NLRP3; however, ASC colocalized with both GFAP and IBA1 cells of the $S O D 1^{\mathrm{G} 93 A}$ mice [12].

To attenuate the neurodegenerative proinflammatory effects of microglia, several therapeutic substances have been used in different SOD1 models. Tempol treatment of $S O D 1^{G 93 A}$ mice reduced the expressions of proinflammatory cytokines Il-1 $\beta$, Tnf $\alpha$ and $i N o s$, whereas Ifn $\gamma$ expression did not show any statistical difference in the spinal cord samples [14]. Gamisoyo-San (GSS) treatment of SOD1 ${ }^{G 93 A}$ mice downregulated the TLR4 signaling related proteins TLR4, CD14 and COX-2 in the spinal cord [28]. Noggin (an antagonist of bone morphogenetic protein)-treated SOD1 ${ }^{\text {His } 46 \mathrm{Arg}}$ transgenic rats showed no statistical difference in IBA1 staining of the spinal cord, when compared to controls, however Western blot and immunostaining of CD68-activated microglia showed less immunoreactivity in the noggin-administered lumbar spinal cords of SOD1 ${ }^{\mathrm{His} 46 \mathrm{Arg}}$ transgenic rats [78]. In the same study, triple immunostaining of IL-1 $\beta$-CD68-GFAP, iNOS-CD68-GFAP and TNF $\alpha$-CD68-GFAP proved that astrocytes predominantly express IL-1 $\beta$, iNOS and $\mathrm{TNF} \alpha$, rather than activated microglia [78]. Furthermore, noggin treatment of SOD1 ${ }^{\text {His } 46 \mathrm{Arg}}$ transgenic rats demonstrated significantly decreased $i N O S$ and TNF $\alpha$ expressions both in astrocytes and microglia, whereas $\mathrm{Il}-1 \beta$ expression particularly decreased in the astrocytes [78]. BMP4-targeted anti-sense oligonucleotide administration of $S O D 1^{H i s 46 A r g}$ rats downregulated CD68-activated microglia; however, IBA1+ microglia were not affected by BMP4 suppression [78]. TAK-242 treatment of $S O D 1^{G 93 A}$ mice decreased Tnfa, but not Il-1 $\beta$ mRNA levels in the spinal cord samples [29]. KCHO-1 treatment of SOD1 ${ }^{\mathrm{G} 93 A}$ mice reduced iNOS expression in the spinal cord when compared to the vehicle-treated samples [18]. Short-term clemastine treatment of $S O D 1^{G 93 A}$ mice insignificantly reduced CD68 and NFKB; however, long term clemastine (1st generation histamine H1R antagonist) treatment produced the opposite effects, when compared to the vehicle-treated mice [24]. AMD3100-treated SOD1 ${ }^{\mathrm{G} 93 A}$ mice revealed significantly reduced TNF $\alpha$ and IL-6 levels in the spinal cord [22].

In addition to proinflammatory cytokines, the effects of anti-inflammatory factors have also been examined in SOD1 models. The number of Arg1+/IBA1+ microglia was significantly higher in the anterior horn of the P90 SOD ${ }^{\mathrm{G} 93 A}$ mice; however, it was reduced at P120 [76]. Concordantly, mRNA levels of M2-type markers Arg-1 and CD206, together with M2-type cytokine $\mathrm{Il}-10$, were increased in P90, but declined in P120 SOD1 ${ }^{\mathrm{G} 93 A}$ mice $^{76}$. Arg1, Fizz1, Socs1, Tgf $\beta 1$ and CD206 mRNAs were found to be significantly decreased in the pre-symptomatic SOD $1^{\mathrm{G} 93 A}$ mice; however, expressions of only Arg1 and Socs1 were reduced in the symptomatic $S O D 1^{\mathrm{G} 93 A}$ mice [11]. On the other hand, increased levels of Tgf $\beta 1$ and CD206 were detected in the symptomatic $S O D 1^{G 93 A}$ mice [11]. Ablation of serotonin $2 \mathrm{~B}$ receptor $\left(5-\mathrm{HT}_{2 \mathrm{~b}}\right)$ in $S O D 1^{\mathrm{G} 86 R}$ mice resulted in reduced mRNA levels of $T g f \beta 1, T g f \beta R 1, Y m 1$ and Tyrobp in the brain stem [27].

To boost the neuroprotective anti-inflammatory effects of microglia, several drug treatments have been carried out using SOD1 models. Increased gene expression levels of the neurotrophic factors BDNF and GDNF were shown to be decreased in tempoland riluzole-treated 14-week-old $S O D 1^{G 93 A}$ mice, respectively [14]. In contrast with the predominant assumption that TGF $\beta$ is an anti-inflammatory cytokine, it can also induce inflammation, acting as a proinflammatory agent [79]. Consequently, the Tgf $\beta$ mRNA level was reduced by tempol administration in $S O D 1^{G 93 A}$ mice, whereas $I l-10$ expression remained at the same level among vehicle-, riluzole- and tempol-treated groups [14]. Ninety-day-old $S O D 1^{G 93 A}$ mice receiving total body irradiation together with intravenous transplantation of GFP+ donor bone marrow cells revealed an accumulation of bonemarrow-originated M2-type microglia in the ventral spinal cord, and this was attributed to the permeability in the blood brain barrier [80]. IL-33 treatment of $S O D 1^{G 93 A}$ mice 
did not alter Arg-1 immunoreactivity in the female group; however, it increased the Arg1 protein expression of the males in the ventral horn [25]. The amounts of Arg1 and CD163 after clemastine treatment of P120 SOD $1^{\mathrm{G} 93 A}$ mice were increased by 2.5 -fold and 3 -fold, respectively, when compared to the wild-types [24]. Additionally, protein levels of purinergic receptors $\mathrm{P} 2 \mathrm{X} 7$ and $\mathrm{P} 2 \mathrm{Y} 12$ after clemastine treatment of P120 SOD $1^{\mathrm{G} 93 \mathrm{~A}}$ mice were increased by 3 -fold and 5-fold, respectively, when compared to the vehicle-treated mice, whereas the P2X4 level remained unchanged [24].

\subsection{Transcriptome Profiling of the SOD1 Models}

Single-cell RNA sequencing analysis of wild-type and mutant SOD1 mice at P100 revealed 227 differentially expressed genes in the microglia of the brain stem, in which Sod1 and Camk2b genes were upregulated and Nav2, mt-Rnr2 and 1700112E06Rik genes were downregulated [81]. TaqMan gene expression assays of SOD1- and Klotho-overexpressing SOD1 mice revealed significant differences-Il-1 $\beta$, Il-12 $a$ and Tnf $\alpha$ mRNAs were downregulated, whereas Mag mRNA was overexpressed in the motor cortex [26]. Furthermore, Fzd5, Il-1 $\alpha$, Tnfaip 2 and Tnf $\alpha$ mRNAs were significantly downregulated, whereas Vegf, Mbp, Mag, Nrf2, Prx-3 and Prx-2 mRNAs were upregulated in the lumbar spinal cord [26]. Spatial transcriptomics of L3 to L5 sections of the spinal cord from both wild-type and mutant SOD1 mice at pre-symptomatic, symptomatic and end-stage time points revealed that upregulation of Iba1, Tyrobp and Trem 2 at the pre-symptomatic phase triggers microgliosis and the formation of the phagocytic microglial phenotype in this ALS model [13]. Transcriptome analysis of microglia from $S O D 1^{G 93 A}$ mice revealed two major gene clusters. Cluster 1 was related to suppressed homeostatic genes including P2ry12, Tmem119, Gpr34, Jun, Olfml3, Csf1r, Hexb, Mertk, Rhob, Cx3Cr1, Tgfbr1 and Tgfb1 and transcription factors such as Mef2a, Mafb, Jun, Sall1 and Egr1, which were enriched in adult microglia; and Cluster 2 was related to upregulated genes including Spp1, Itgax, Axl, Lilrb4, Clec7a, Ccl2, Csf1 and Apoe [82]. Microglia from $S O D 1^{G 93 A}$ spinal cords showed a negative correlation in the expression levels of Mef2a, Sall1 and Tgfbr1 but a positive correlation in Apoe expression with the progression of disease [82]. In the microglia of $S O D 1^{\mathrm{G} 93 A} \mathrm{Trem}^{-1-}$ mice, 11 out of 36 downregulated inflammatory genes were identified, and in the microglia of $S O D 1^{\mathrm{G} 93 A} \mathrm{Trem}^{+/-}$ mice 66 out of 240 suppressed homeostatic genes were identified [82]. Clec7a ${ }^{+}$P2ry12microglia were detected in the spinal cord of $S O D 1^{\mathrm{G} 93 A} \mathrm{Trem}^{+/-}$mice at P115, whereas Clec7a- P2ry12 ${ }^{+}$homeostatic microglia were detected in the SOD1 ${ }^{\mathrm{G} 93 A} \mathrm{Trem}^{-/-}$mice [82]. Male SOD1 ${ }^{\mathrm{G} 93 A} \mathrm{Trem}^{+/-}$mice showed Apoe induction; however, Trem 2 deletion in these males suppressed Apoe and restored the homeostatic microglial genes including Spi1 (PU.1), Smad3, Tgfbr1 and Sall1, when compared to females through RNAseq analysis [82]. Additionally, miR-155 expression was not detected in SOD1 ${ }^{\mathrm{G}^{93} \mathrm{~A}} \mathrm{Trem}^{-1-}$ mice [82]. miR-155 was found to be increased in the spinal cord of the pre-symptomatic and symptomatic $S O D 1^{\text {G93A }}$ mice; however, miR-125b, miR-146a, miR-21 and miR-124 were increased only in the symptomatic $S O D 1^{G 93 A}$ mice [11]. Gene ontology enrichment and network analysis of $S O D 1^{G 93 A}$ microglia revealed transcriptional differences in the genes responsible for the regulation of the immune response (for example, upregulation of $\mathrm{Ccl5}$ and $\mathrm{Cxcl13}$, downregulation of $\alpha$-synuclein), chemotaxis (for example, upregulation of Spp1), DNA damage (for example, upregulation of Brca1, P21, Pcna and Stat1 and downregulation of Gadd45a, Sp3), angiogenesis, inflammation, blood coagulation and hypoxia processes [83]. All of these mentioned changes in different $\mathrm{CNS}$ regions regarding microglial markers and transcriptome profiling of different SOD1 mice is depicted in Table 2. 
Table 2. Microglial alterations in different SOD1 animal models based on the age, tissue and method.

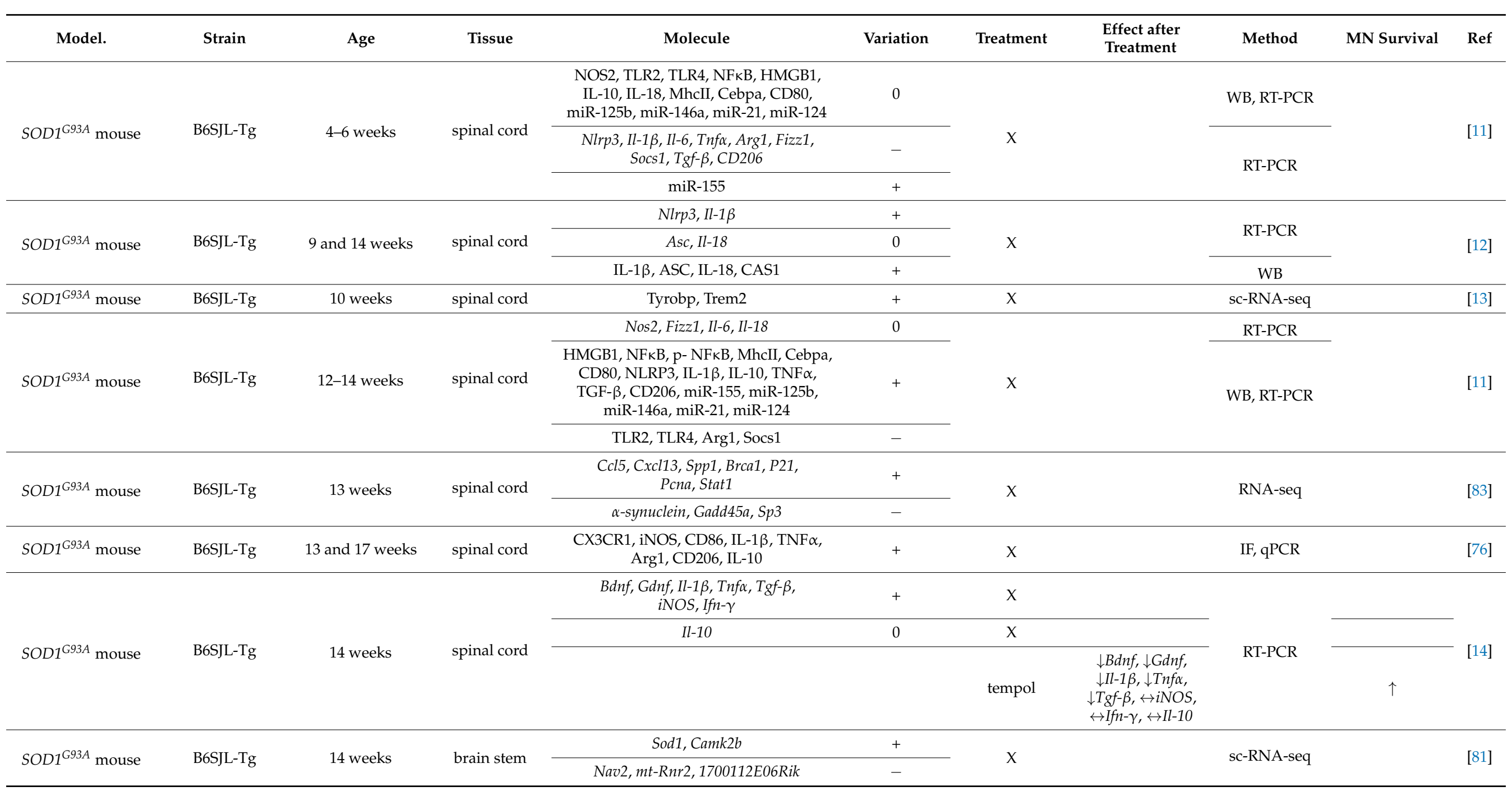


Table 2. Cont.

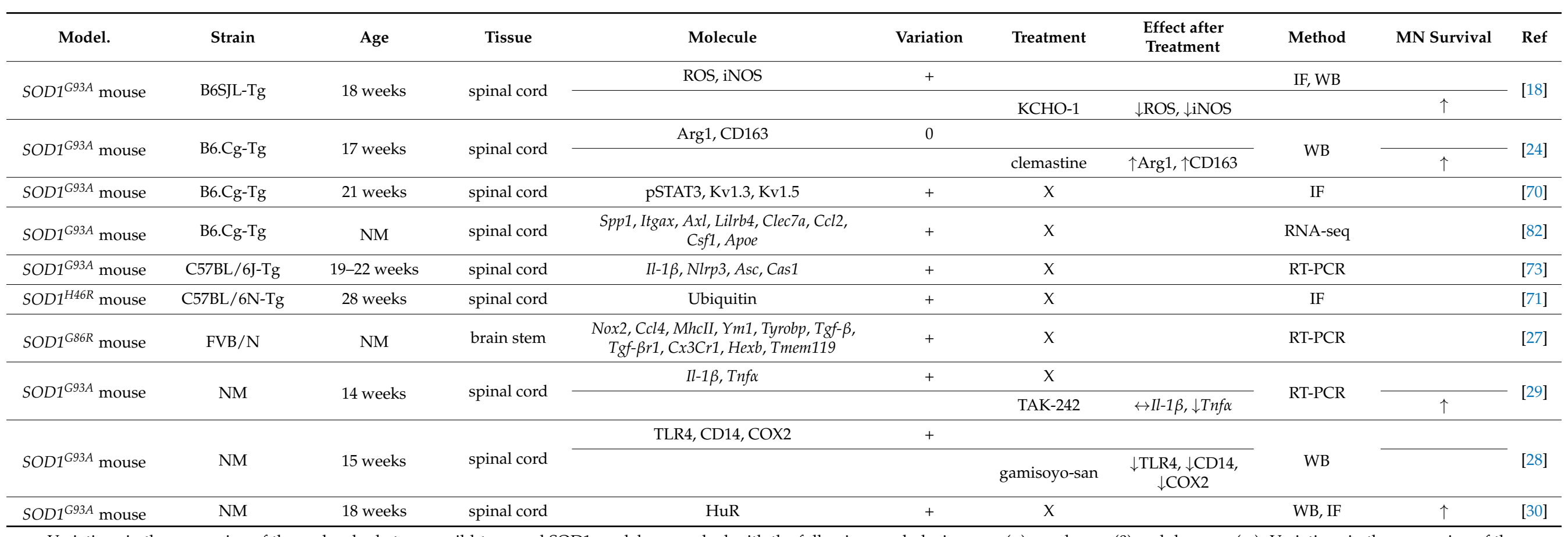

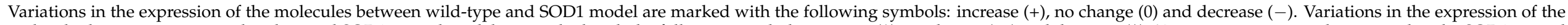

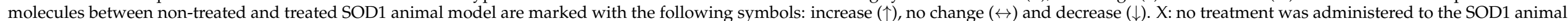

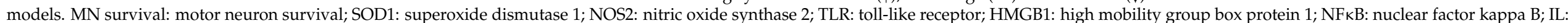

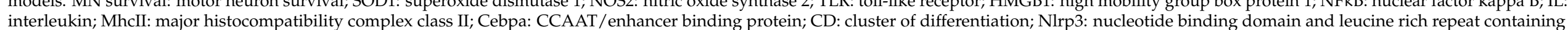

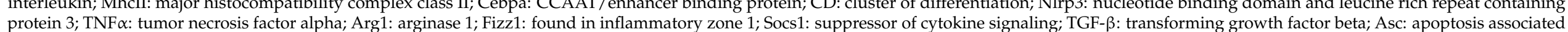

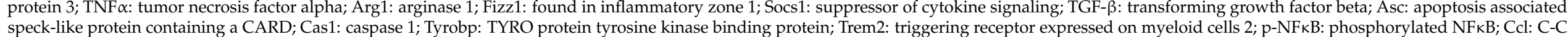

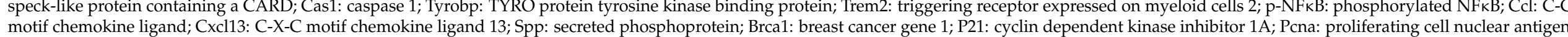

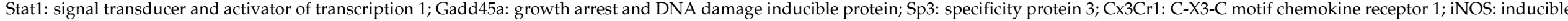

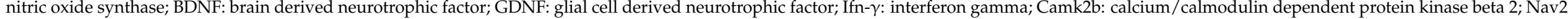

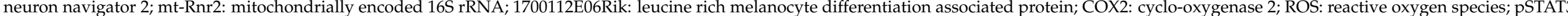

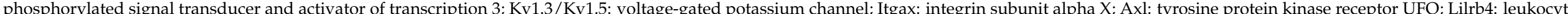

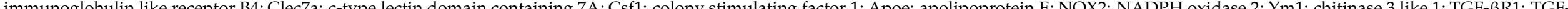
transcription polymerase chain reaction; qPCR: quantitative polymerase chain reaction; RNA-seq: RNA sequencing; sc-RNA-seq: single-cell RNA seq; NM: not mentioned. 


\subsection{Summary of the Microglial Characteristics of the SOD1 Models}

The first mutation that was associated with ALS was discovered to be included in the SOD1 gene. The effects of the mutation in this gene, which codes for a detoxification enzyme, have been the focus of many studies aiming to interpret the pathological consequences of ALS disease more comprehensively. For this purpose, animals with $S O D 1^{G 93 A}$ mutation on the B6SJL background were commonly utilized. Starting from the onset of the disease, increased microgliosis, together with elevated levels of neuroinflammation and NLRP3 inflammasome activation were detected as the main changes observed in microglia. Surprisingly, upregulation of anti-inflammatory cytokines was also observed, starting from the onset of the disease in the $S O D 1^{G 93 A}$ mice. Finally, neuroprotective cytokines fail to provide the neurodegenerative counterbalance that causes microglia to induce non-cell autonomous motor neuron cell death. A large number of compounds intended to counteract the excess proinflammatory functions of microglia have been extensively studied to alleviate ALS symptoms. For example, tempol administration to both pre-symptomatic and symptomatic SOD $1^{\mathrm{G} 93 \mathrm{~A}}$ mice and $\mathrm{KCHO}$ administration to pre-symptomatic $S O D 1^{\mathrm{G} 93 \mathrm{~A}}$ mice on the B6SJL background enhanced motor neuron survival by inhibiting proinflammatory cytokines and acting through the ROS/NOS mechanism, respectively. Similarly, clemastine treatment of pre-symptomatic $S O D 1^{G 93 A}$ mice with a B6.Cg genetic background promoted both the production of anti-inflammatory cytokines and motor neuron survival. Furthermore, TAK-242 treatment at the early symptomatic phase and GSS treatment symptomatic of $S O D 1^{\mathrm{G} 93 \mathrm{~A}}$ mice cut down the release of proinflammatory cytokines, and probably supported motor neuron survival.

Having now acknowledged that many proinflammatory factors are secreted by $\mathrm{mi}-$ croglia, indicating increased inflammatory activity, we have outlined putative signaling pathways that could explain the characteristics found in the spinal cord of $S O D 1^{G 93 A}$ mice (Figure 2).

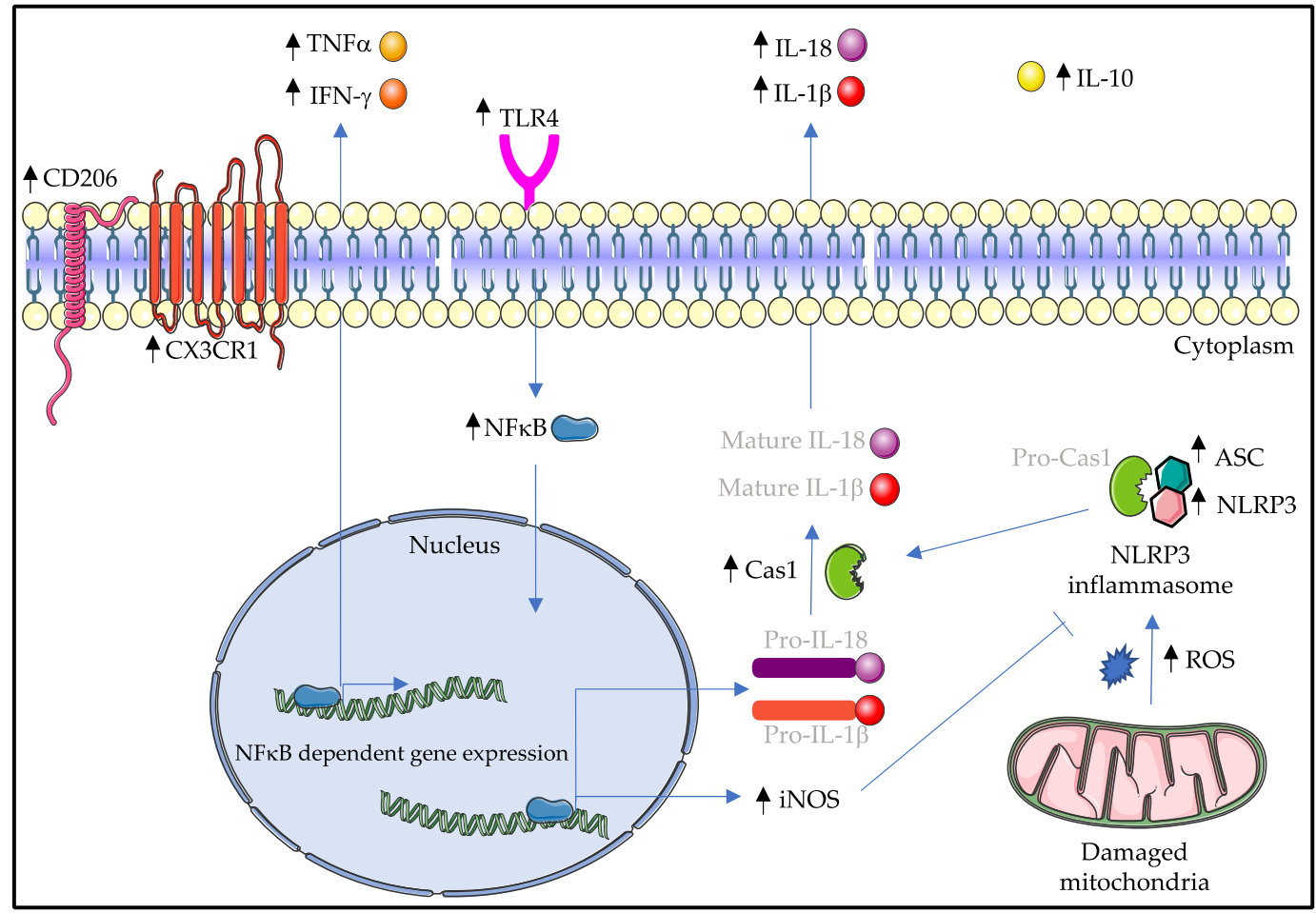

Figure 2. Possible signaling cascades in the spinal cord microglia of the symptomatic SOD1G93A mice. Activation of

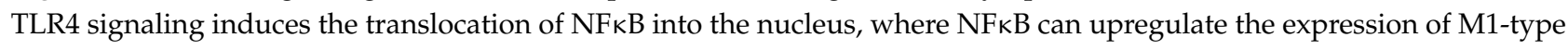
proinflammatory cytokines such as TNF $\alpha$, IFN- $\gamma$, iNOS, Pro-IL-1 $\beta$ and Pro-IL-18. Furthermore, increased production of reactive oxygen species by damaged mitochondria induces the activation of NLRP3 inflammasome, ultimately leading to 
the cleavage of IL-1 $\beta$ and IL-18 molecules. Surprisingly, M2-type microglia markers IL-10 and CD206 are upregulated. The balance between M1 and M2 activation states is broken down in symptomatic SOD1G93A mice, and M1-type microglia outweigh M2-type microglia, causing microgliosis and eventually motor neuron degeneration. Molecules that are written in light gray are not mentioned in this review. Black arrows indicate an increase in the amount of the respective molecule. CD206: cluster of differentiation 206; CX3CR1: C-X3-C motif chemokine receptor 1; TNF $\alpha$ : tumor necrosis factor alpha; IFN- $\gamma$ : interferon gamma; TLR4: toll-like receptor 4; IL: interleukin; NFkB: nuclear factor kappa B; Cas1: caspase 1; iNOS: inducible nitric oxide synthase; ASC: apoptosis associated speck-like protein containing a CARD; NLRP3: nucleotide binding domain and leucine rich repeat containing protein 3; ROS: reactive oxygen species.

\section{C9Orf72 Model}

A characteristic that accounts for the largest proportion of both familial and sporadic cases of human ALS in Europe is an expansion of a hexanucleotide repeat (GGGGCC) in the 1st intron of C9Orf72 [60,84]. In Europe, approximately 30\% of fALS patients and 5\% of sALS patients have been identified with expansions in the C9Orf72 gene [60]. Healthy individuals carry 2-22 repeat expansions, whereas ALS patients can have hundreds or thousands of repeats in the C9Orf72 region [85]. Despite being the most common genetic mutation related to ALS, the function of C9Orf72 remains unclear. Several mechanisms have been proposed to describe C9Orf72-mediated ALS and all of them are not mutually exclusive [86]. Initial studies suggested that C9Orf72 expansion may be a loss-of-function mutation after an approximately $40 \%$ reduction in mRNA levels of C9Orf72 was found in the frontal cortex of ALS patients [87]. The second hypothesis is that the transcribed extensions of C9Orf72 form nuclear RNA foci that can sequester RNA-binding proteins and disrupt RNA homeostasis [87]. Finally, the repeat-associated non-ATG (RAN) translation of hexanucleotide repeats can cause aggregation of dipeptide repeat (DPR) proteins (such as poly-GA, -GP, -GR, -PA and -PR), leading to toxicity and cellular dysfunction [88]. So far, it has been challenging to create a suitable genetically modified model with a C9Orf72-background that resembles human ALS. Knockout mice that exhibited a general or cell-specific loss of C9Orf72 showed no motor or neurodegenerative abnormalities [89]. However, the same study demonstrated that C9Orf72 was essential for the balanced functionality of microglia [89]. Since the mentioned hexanucleotide repeats are assumed to lead to translation and accumulation of DPRs, models overexpressing these have also been used. However, it was also shown that the phenotype of this model was strongly dependent on the type and frequency of expressed DPRs [31,90-93]. One of the end-stage poly-GA mouse models needed to be euthanized by 7 weeks of age, due to the severity of the symptoms [31]. In another poly-GA model, when adeno-associated virus vaccination was carried out in the pre-symptomatic stage, it was shown to be effective. Thus, ALS disease progression also differs depending on the C9Orf72 model used, as reviewed in Batra and Lee, 2017 [94].

\subsection{Microglial Morphology of the C9Orf72 Models}

Three-week-old poly-GA mice exhibited activated amoeboid microglia in the CA2 region of the hippocampus, as shown by IBA1 staining, whereas both affected and asymptomatic poly-PR mice showed normal ramified morphology in the hippocampus region [31]. The density and the area of IBA1+ cells were reduced, together with the morphological alteration from amoeboid to ramified shape in ovalbumin-(GA) 10 -immunized poly-GA mice, when compared to control groups [33]. A promoter activity of the mouse ortholog of C9Orf72 was detected in a few IBA1-stained microglia in the 5th layer of the primary motor cortex $(15.2 \%)$, primary somatosensory cortex $(16.0 \%)$, dorsal $(13.2 \%)$ and the ventral (5.9\%) spinal cord using C9Orf72 $2^{\mathrm{Lacz}+/-}$ mice [95]. Immunohistochemistry and qPCR results of the spinal cord of 6-month-old poly-GA-CFP mice showed a significant upregulation of phagocytic microglia markers CD68 and IBA1 [32]. IBA1 was also found to be increased in GFP-(GR) 100 mice on both the mRNA and protein level [34]. As a modifier of frontotemporal lobe dementia (FTLD) risk, transmembrane protein 106b (Tmem106b) was examined in Tmem106b+/ +, +/ - and -/ - mice, which were injected with adeno 
associated virus-(GGGGCC) 66 , and which showed no statistical differences in their Iba1 mRNA levels [96]. Similarly, mice injected with AAV1-GFP (control group), AAV1-GFP$(G A)_{50}$ (poly-GA group) and AAV1-GFP-(GA) 50 -mut (disrupted poly-GA group) revealed no statistical differences in the Iba1 mRNA levels [97].

Microglia of C9Orf $72^{-/-}$mice showed aggregation of lysotracker and Lamp1+ enlarged vesicles, together with increased levels of Il-6 and Il-1 $\beta$ cytokines, which could support the idea that changes in lysosomal function lead to neuroinflammation [89]. Molecular changes in the microglia of different C9Orf72 models are summarized in Table 3.

Table 3. Microglial alterations in C9Orf72 mice based on the age, collected tissue and method.

\begin{tabular}{cccccccc}
\hline Model. & Strain & Age & Tissue & Molecule & Variation & Method & Reference \\
\hline Poly-GA mouse & C57BL/6 & 10 weeks & spinal cord & Cyr61 & + & RNA-seq & [98] \\
\hline Poly-GA mouse & C57BL/6J-Tg & 28 weeks & spinal cord & Ccl4, Grn, Tyrobp & + & RNA-seq & [33] \\
\hline Poly-GA mouse & C57BL/6N-Tg & 7 weeks & brain & $\begin{array}{c}M x 1, I s g 15, \\
\text { Oasl1/2, C3, C4b }\end{array}$ & + & RNA-seq & [31] \\
\hline C9Orf72-/- mouse & C57BL/6J-Tg & N/A & spinal cord & Il-1 $3, I l-6$ & + & qRT-PCR & [89] \\
\hline
\end{tabular}

Variations are symbolized in terms of an increase (+) as compared to the age-matched wild type littermates. N/A: not applicable; Cyr61: cysteine rich angiogenic inducer 61; Ccl: C-C motif chemokine ligand; Grn: granulin; Tyrobp: TYRO protein tyrosine kinase binding protein; Mx1: interferon induced GTP binding protein Mx1; Isg15: interferon stimulated gene 15; Oasl1/2: 2'-5'-oligoadenylate synthase-like protein 1; C3: complement component 3; C4b: complement component 4b; IL: interleukin; RNA-seq: RNA sequencing; qRT-PCR: quantitative reverse transcription polymerase chain reaction.

\subsection{Transcriptome Profiling of the C9Orf72 Models}

RNA sequencing analysis revealed upregulation of the immune response, including cytokine/chemokine mediated signaling and interferon-inducible genes in the brain samples of end-stage poly-GA mice, of which the expressions were correlated with the spinal cord and motor cortex samples from both ALS and C9Orf72-ALS patients [31]. Specifically, isolated microglia from poly-GA mice showed differential expression of interferon-stimulated genes such as Mx1, Isg15 and Oasl1/2 and complement factors like C3 and C4b in the transcriptome analysis [31]. Gene set enrichment analysis (GSEA) on RNA-seq samples from 17-month-old C9Orf72-/- mice revealed that a third (6 out of 19) of the upregulated pathways were related to neuroinflammation (such as interferon signaling), in which the majority (10 out of 19) of the pathways also showed upregulation in C9Orf72-ALS patients [89]. Similarly, transcriptome analysis of spinal cord samples revealed that there were 233 differentially expressed genes between transgenic-PBS (TG-PBS) and ovalbumin(GA) 10 -immunized poly-GA groups, where ovalbumin-(GA) 10 vaccination was able to attenuate several immune pathways (for instance, induction of C-C motif chemokine ligand 4, granulin, TYRO protein tyrosine kinase binding protein and complement factors), which were triggered in poly-GA mice [33]. Genome-wide identification of RNAs from C9Orf72 antisense oligonucleotide (ASO)- and control ASO-treated mice revealed only a few RNA expression changes in the spinal cord samples, including C9Orf72 itself and Cyr61 genes [98].

\subsection{Summary of Microglial Characteristics of the C9Orf72 Models}

Hexanucleotide repeat expansions in the intronic region of the C9Orf72 gene have been described as the major genetic cause of ALS. Since its discovery, several genetically altered animal models and adeno-associated virus injection methods have been utilized to examine these expansions in detail. Surprisingly, there are only few studies investigating proinflammatory cytokines in this model. For example, interleukin release was detected in the C9Orf72 knock-out mice. Additionally, mice overexpressing DPRs such as poly-GA and poly-GR demonstrated higher levels of microgliosis. Preferentially, studies in C9Orf72 models were mainly concentrated on transcriptome profiling. These analyses of the C9Orf72 
models confirmed the upregulation of the genes related to neuroinflammation and immune pathways, especially including interferon-stimulated genes and complement factors.

\section{TDP-43 Model}

Even though mutations in transactive response DNA binding protein 43 (TARDBP or TDP-43) are rather rare in ALS patients, a mutation in about $4 \%$ of all European familial ALS cases can be found with an associated protein accumulation in the cytosol of affected cells; this process appears to play a role in the pathology of some ALS cases, although it remains unclear how these mutations cause ALS [60]. TDP-43 is a DNA and RNA binding protein, containing nuclear localization and export signals, a glycine-rich C-terminal domain and two RNA recognition motifs [99]. It plays role in RNA transcription, splicing, transport, stabilization and microRNA biogenesis [100]. TDP-43 is normally localized in the nucleus; however, under pathological conditions, it aggregates in the cytosol. The nuclear loss of TDP-43, together with its cytosolic accumulation, was shown to be involved in both ALS and FTLD pathogenesis [101]. The cleaved form of TDP-43 is the main component of the ubiquitinated and hyperphosphorylated inclusions that are present in neurons and glial cells of some ALS cases [101,102]. Until now, about 40 mutations in the TDP-43 gene have been associated with ALS (http:/ / www.hgmd.org, accessed in January 2021). Many of these mutations have already been introduced into an animal model to study the pathology and effects of this mutations, as reviewed in McGoldrick et al., 2013 [103]. Unfortunately, it was also found that the phenotype is strongly dependent on the genetic background of the model and the promoter used, as well as the level of the transgene expression. Thus, the findings of this animal model must still be considered with limitations [86]. Since the TDP-43 mouse models for ALS are dependent on many individual factors, it is also not easy to define a uniform course of disease, so correlation or comparison with other ALS models appears difficult.

\subsection{Microglial Morphology of the TDP-43 Models}

Increased amounts of $\mathrm{C} 5 \mathrm{aR} 1$, the main receptor of the proinflammatory complement peptide, and $\mathrm{C1q}$, one of the complement components, were demonstrated to be localized in the microglia by double immunostaining with IBA1 in 16-month-old TDP-43 ${ }^{\mathrm{Q} 331 \mathrm{~K}}$ mice [35]. Additionally, mRNA expressions of complement components $C 1 q B, C 3$ and $C 4$ were increased; on the other hand, CD55 was decreased both in the spinal cord samples from 10- and 16-month-old TDP-43Q331K mice, without altering C5a, $f B$ and $C D 59 a$ levels [35]. The number of activated IBA1+ microglia in $p r p T D P-43^{A 315 T}$ UCHL1eGFP mice (having TDP-43 pathology in eGFP-labeled corticospinal motor neurons) increased with the disease progression, starting at P90 in the layer 2/3 and at P60 in the layer 5 of the motor cortex [36]. Additionally, affected upper motor neurons were found at close proximity to rod-like microglia [36]. Treatment of TDP- $43^{A 315 T}$ mice with root extract of anti-inflammatory Withania somnifera (ashwagandha) attenuated microgliosis and restored a less reactive microglia phenotype, as demonstrated in IBA1 staining [104].

The percentage of $\mathrm{CD} 11 \mathrm{~b}+$ microglia and the number of amoeboid microglia were increased in the spinal cords of 16-month-old TDP-43 $3^{\mathrm{Q} 331 \mathrm{~K}}$ mice, when compared to nontransgenic and wild-type TDP-43 mice [35]. Furthermore, female TDP- $43^{A 315 T}$ mice showed a two-fold increase in CD11b staining, and TDP- $43^{A 315 T} S M N$ (SMN: survival motor neuron) double transgenic mice attenuated the microglial activation relative to spinal cord samples of TDP-43 ${ }^{A 315 T}$ mice [37]. Chronic intraperitoneal injection of lipopolysaccharide (LPS) to heterozygous TDP-43 ${ }^{A 315 T}$ mice revealed cytoplasmic TDP-43 aggregations in LPS activated microglia, as shown by CD11b immunostaining [105].

\subsection{Microglial Markers in the TDP-43 Models}

No change in TNF $\alpha$ was detected in the spinal cords of ashwagandha-treated TDP$43^{A 315 T}$ mice; however, spinal cord extracts of ashwagandha-treated TDP-43 ${ }^{A 315 T}$ mice revealed less NFKB activation [104]. On the other hand, M2-type microglia markers Ym-1 
and Arginase1 were shown to be increased in ashwagandha-treated TDP-43 ${ }^{A 315 T}$ mice [104]. The molecular changes in the microglia of TDP-43 mice have been listed in Table 4.

Table 4. Microglial alterations in TDP-43 animal models based on the age, collected tissue and method.

\begin{tabular}{|c|c|c|c|c|c|c|c|}
\hline Model. & Strain & Age & Tissue & Molecule & Variation & Method & Reference \\
\hline$T D P-43^{Q 331 K}$ mouse & C57BL/6J-Tg & 10 and 16 months & spinal cord & $\begin{array}{c}C 1 q B, C 4, C 3 \\
C 5 a R 1, C 1 q\end{array}$ & + & RT-PCR, IF & {$[35]$} \\
\hline$T D P-43^{Q 331 K}$ mouse & C57BL/6J-Tg & 10 and 16 months & spinal cord & $f B, C D 59 a, C 5 a$ & 0 & RT-PCR & [35] \\
\hline TDP-43 $3^{Q 331 K}$ mouse & C57BL/6J-Tg & 10 and 16 months & spinal cord & CD55 & - & RT-PCR & [35] \\
\hline$T D P-43^{A 315 T}$ mouse * & C57BL/6-Tg & $\mathrm{N} / \mathrm{A}$ & spinal cord & Ym1, Arg1 & + & WB & {$[104]$} \\
\hline$T D P-43^{A 315 T}$ mouse * & C57BL/6-Tg & $\mathrm{N} / \mathrm{A}$ & spinal cord & $\operatorname{Tnf} \alpha$ & 0 & WB & [104] \\
\hline$T D P-43^{A 315 T}$ mouse * & C57BL/6-Tg & $\mathrm{N} / \mathrm{A}$ & spinal cord & p65 of NFkB & - & WB & [104] \\
\hline
\end{tabular}

Variations are symbolized in terms of increase $(+)$, no change $(0)$ and decrease $(-)$ as compared to age-matched wild-type littermates. $\left({ }^{*}\right.$ In this study, vehicle treated TDP- $43^{A 315 T}$ mice were compared to ashwagandha-treated TDP- $43^{A 315 T}$ mice.) N/A: not applicable; C1q: complement component 1q; C3: complement component 3; C4: complement component 4; C1qB: C1q beta polypeptide; C5a: complement component 5a; C5aR1: C5a receptor 1; fB: complement factor B; CD59a: complement regulator; CD55: complement regulator; Ym1: chitinase 3 like 1; Arg1: arginase 1; Tnf $\alpha$ : tumor necrosis factor alpha; NFKB: nuclear factor kappa B; RT-PCR: reverse transcription polymerase chain reaction, IF: immunofluorescent staining; WB: Western blotting.

\subsection{Summary of the Microglial Characteristics of the TDP-43 Models}

After the detection of mutations in the TDP-43 gene of human ALS patients, TDP-43 animal models drew attention. However, studies concerning microglia in these mouse models are scarce. In one study, complement components, which drive the proinflammatory pathways, were found to be deregulated in TDP- $43^{Q 331 K}$ mice. In another study, ashwagandha treatment of TDP- $43^{A 315 T}$ mice enhanced anti-inflammatory cytokines and reduced neuroinflammation possibly by acting on the NFKB signaling pathway.

\section{Wobbler Mouse Model}

The wobbler mouse, having an autosomal recessive wobbler (wr) mutation, was first described by Falconer in 1956 [106] in an C57BL/Fa mouse strain. It was shown that affected C54BL/6J mice have a spontaneous mutation in the vacuolar protein sorting-associated protein 54 (Vps54) gene, which encodes for one of the components of the Golgi-associated retrograde protein (GARP) complex [107]. This complex plays a role in the retrograde vesicular transport of molecules from early/late endosomes to recycling endosomes and the trans-Golgi network (TGN). Nowadays, models with two different genetic backgrounds are available to study the consequences of this naturally occurring Vps54 mutation: C57BL/6Jwr and NFR-wr. The homozygous wr mutation causes a destabilization of the VPS54 protein, which in turn destabilizes the GARP complex, leading to the progressive loss of upper and lower motor neurons. As the wobbler mutation occurred spontaneously, this animal model was considered for the sporadic form of ALS. In some of the ALS cases, patients were identified with the Vps54 mutation through the Project MinE study (http:/ / databrowser.projectmine.com, accessed in January 2021). Based on the severity of physical symptoms, wobbler mice can be grouped into three phases: (1) pre-symptomatic, (2) early clinical (evolutionary) and (3) stabilized (stable clinical). The pre-symptomatic phase lasts from birth to 3 weeks of age. During this phase, there is almost no difference between wild-type and wobbler mice in terms of clinical symptoms [108]. The early clinical phase lasts from 3 weeks to 3 months of age, when wobbler mice usually develop symptoms such as having head tremors, muscle atrophy, wobbly gait and reduced body weight [108]. The stabilized phase, which lasts from 3 months of age to death, can be identified by the arrest of motor neuron degeneration [108]. Wobbler mice at the stable clinical stage show enlarged endosome vacuolization, impaired anterograde/retrograde axonal transport, protein aggregation and mitochondrial dysfunction in the motor neurons, in addition to neuroinflammation, such as astrogliosis and microgliosis [109]. 


\subsection{Microglial Morphology of Wobbler Mice}

Several studies have shown neuroinflammation in different regions of the CNS of wobbler mice. The motor cortex of P20 to P60 wobbler mice showed an increased number of IBA1-labeled microglial cells [38]. P20, P40 and P60 wobbler mice also have activated microglia in all three layers of the cerebellum and white matter [39]. Increased TNF $\alpha$ was also demonstrated in the motor cortex and cerebellum of P40 wobbler mice by double immunostaining with IBA1 [38,39]. The percentage of amoeboid shaped IBA1+ microglia was increased in the dentate gyrus, and treatment with a glucocorticoid receptor antagonist, CORT108297, reinstated the ramified phenotype in the wobbler mice [45]. Similarly, the increased number of IBA1+ cells was significantly decreased in the spinal cord sections of wobbler mice with short-term (4 days) and long-term (21 days) treatment with glucocorticoid receptor modulator CORT113176 [46,47]. In other studies, the high density of IBA1+ cells in the spinal cords was reduced when wobbler mice were treated with neuroactive steroids progesterone [42], synthetic progestin norethindrone [42] and high-affinity progesterone receptor agonist nestorone [48], respectively. Progesterone and nestorone were also able to change the amoeboid structure of microglia to a less reactive phenotype [42,48].

Reverse transcription polymerase chain reaction (RT-PCR) analysis of CD11b mRNA showed an increase in the spinal cord samples of wobbler mice, which was reduced with CORT113176 treatment $[46,47]$. In another study, progesterone treatment was shown to decrease $C D 11 b$ mRNA levels in the wobbler mice compared to the control group, whereas norethindrone failed to perform such an effect [42]. Wobbler mice which were treated with nestorone [48] and nonhematopoietic erythropoietin derivatives carbamylated erythropoietin (CEPO) and asialo erythropoietin (ASIALO-EPO) [44] in individual studies demonstrated lowered levels of CD11b. Increased colocalization of CD11b with TNF $\alpha[40,43]$ and TNF $\alpha$ receptor 1 (TNFR1) [40] in the cervical spinal cord of wobbler mice was reduced with treatments of glutamate release inhibitor riluzole, an approved drug against ALS [43], and a toll-like receptor 4 (TLR4) antagonist, VB3323 [43]. Surprisingly, treatment of wobbler mice with PRE-084, an agonist of endoplasmic reticulum resident receptor with chaperone-like activity (S1R), showed an increment in the number of CD11b+ cells in the white matter of the spinal cord, which was contributed to the increase in the numbers of both CD68+ (M1-type microglia) and CD206+ (M2-type microglia) cells [41].

\subsection{Microglial Markers in the Wobbler Mouse}

The expression and release of proinflammatory cytokines such as TNF $\alpha$ and interleukins, together with the stimulation of TLR4 signaling, are the hallmarks of M1 activated microglia. The cerebella of wobbler mice displayed significantly increased expression of TNF $\alpha$ at P40 and Il-1 $\beta$ at both P20 and P40 time points [39]. Spinal cord samples of wobbler mice showed an increase in Il-1 $\beta$ and Tnf $\alpha$ on the mRNA level, and treatment with Sigma-1 receptor agonist PRE-084 was not able to change this inflammatory response [41]. Similarly, treatment of wobbler mice with recombinant human $\mathrm{TNF} \alpha$-binding protein 1 (rhTBP-1) could not change TNF $\alpha$ and TNFR1 protein expressions [40]. In another study, wobbler mice showed upregulated Tnf $\alpha$ and inducible NOS (iNos) mRNAs, which were significantly lowered by nestorone treatment [48]. A decrease in NFKB, along with an increase in inhibitor of kappa B (ІкB) $\alpha$ in the spinal cord samples of the nestorone administered wobbler mice, proved its anti-inflammatory effects, without affecting the TLR4 expression [48]. HMGB1, a ligand of TLR4, in the wobbler microglia was also illustrated by means of a double immunofluorescence experiment with IBA1 [46]. The increased number of HMGB1+ and TLR4+ cells in the spinal cord sections was downregulated by both shortand long-term in vivo CORT113176 treatments of wobbler mice $[46,47]$. mRNA levels

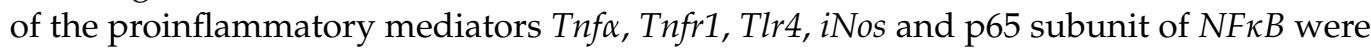
shown to be elevated in wobbler mice, and their expressions were attenuated by short-term treatment with CORT113176 [46]. Similarly, long-term treatment of wobbler mice with CORT113176 significantly decreased the mRNA levels of TLR4, myeloid differentiation primary response 88 (MyD88), Tnfr and Il-18 [47]. Increased amounts of Tnfa, Tlr4 and 
iNos mRNAs were decreased by progesterone treatment, whereas norethindrone failed to perform such an effect [48]. Both progesterone and norethindrone treatment in wobbler mice increased $I \kappa B \alpha$ mRNA levels, however only progesterone increased the mRNA level of the p65 subunit of $N F \kappa B$ [48].

The alternative M2 microglial activation is responsible for the production of antiinflammatory molecules. Even though the M2 activation state does not attract enough attention, when compared to the M1 activation state, M2 markers have also been investigated in several studies. It was shown that $T g f-\beta$ gene expression was upregulated in the cerebellum of the P40 wobbler mice [39]. Furthermore, progesterone treatment of wobbler mice increased the expression level of Tgf- $\beta$ mRNA [42]. The molecular changes in the microglia of wobbler mice have been summarized in Table 5 . 
Table 5. Microglial alterations in wobbler mice based on the age, collected tissue and method.

\begin{tabular}{|c|c|c|c|c|c|c|c|c|c|c|}
\hline Model. & Strain & Age & Tissue & Molecule & Variation & Treatment & Molecule after Treatment & Method & MN Survival & Ref \\
\hline$W r$ mouse & C57BL/6J-wr & $\mathrm{P} 40$ & motor cortex & $\mathrm{TNF} \alpha$, Cas3 & + & $x$ & & IF & & [38] \\
\hline$W r$ mouse & C57BL/6J-wr & $\mathrm{P} 40$ & cerebellum & $\operatorname{Tnf} \alpha, \operatorname{Tgf}-\beta$ & + & $x$ & & RT-PCR & & [39] \\
\hline$W r$ mouse & C57BL/6J-wr & $\mathrm{P} 20$ and P40 & cerebellum & Il-1 $\beta$, Il-10 & + & $x$ & & RT-PCR & & [39] \\
\hline$W r$ mouse & NFR/wr & P28 & spinal cord & $\mathrm{TNF} \alpha, \mathrm{CD} 11 \mathrm{~b}$ & + & $X$ & & IF & & [40] \\
\hline$W r$ mouse & NFR/wr & P63 & spinal cord & 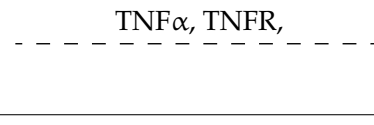 & -+- & $\begin{array}{l}----- \\
\text { rhTBP-1 }\end{array}$ & $\begin{array}{c}\leftrightarrow \mathrm{TNF} \alpha, \dot{\leftrightarrow} \overline{\mathrm{TN}} \overline{\mathrm{N} R},{ }^{\downarrow \mathrm{CD} 11 \mathrm{~b}} \\
\end{array}$ & IF & $\underset{\uparrow}{-----}$ & [40] \\
\hline$W r$ mouse & NFR/wr & P70 & spinal cord & ------------ & --- & ----- & ----------- & IF & $--_{\uparrow}^{-}---$ & [43] \\
\hline$W r$ mouse & NFR/wr & P70 & spinal cord & 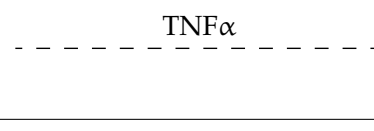 & +-- & $\begin{array}{c}----- \\
\text { VB3323 }\end{array}$ & 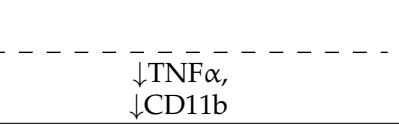 & IF & $\frac{\uparrow}{------}$ & [43] \\
\hline$W r$ mouse & NFR/wr & P84 & spinal cord & 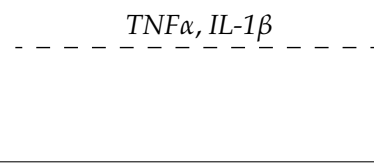 & +- & $\begin{array}{c}----- \\
\text { PRE-084 }\end{array}$ & $\begin{array}{l}\leftrightarrow \bar{T} \bar{N} F \bar{\alpha}, \bar{\leftrightarrow} \bar{I} L-\bar{\beta} \bar{\beta}, \\
\quad \uparrow C D 68, \\
\uparrow C D 206\end{array}$ & IF, RT-PCR & $\begin{array}{c}-\cdots--- \\
\uparrow\end{array}$ & [41] \\
\hline$W r$ mouse & NFR/wr & P150 & spinal cord & $\begin{array}{c}\text { HMGB1, TLR4, IBA1, } \\
\text { CD11b, TNF } \alpha, \text { TNFR, iNOS, } \\
\text { p65 of NFKB } \\
----\end{array}$ & $\begin{array}{c}+ \\
---- \\
---\end{array}$ & CORT113176 & 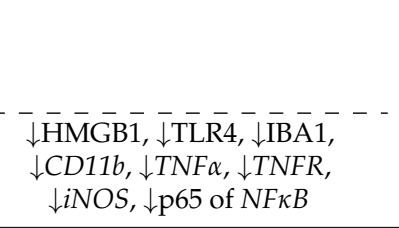 & IHC, RT-PCR & $\begin{array}{c}------ \\
\uparrow\end{array}$ & [46] \\
\hline$W r$ mouse & NFR/wr & P150 & spinal cord & 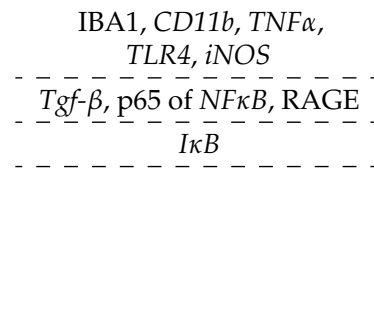 & $\begin{array}{c}+ \\
---- \\
---- \\
-----\end{array}$ & $\begin{array}{l} \\
------ \\
------ \\
------ \\
\text { progesterone }\end{array}$ & 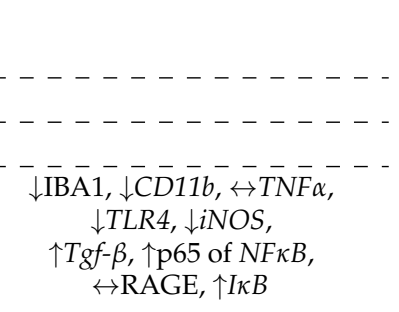 & IHC, RT-PCR & $\begin{array}{c}------- \\
------- \\
------- \\
\uparrow\end{array}$ & [42] \\
\hline
\end{tabular}


Table 5. Cont.

\begin{tabular}{|c|c|c|c|c|c|c|c|c|c|}
\hline Model. & Strain & Age & Tissue & Variation & Treatment & Molecule after Treatment & Method & MN Survival & Ref \\
\hline$W r$ mouse & NFR/wr & P150 & spinal cord & 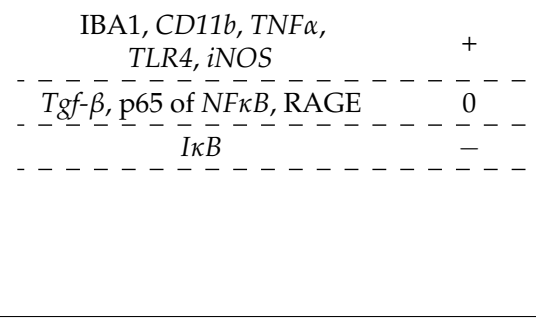 & $\begin{array}{l}---- \\
----- \\
\text { norethindron }\end{array}$ & 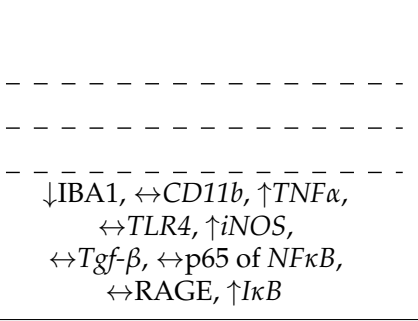 & IHC, RT-PCR & $\begin{array}{c}------ \\
------ \\
------ \\
\leftrightarrow\end{array}$ & [42] \\
\hline Wr mouse & $\mathrm{NFR} / \mathrm{wr}$ & P150 & spinal cord & 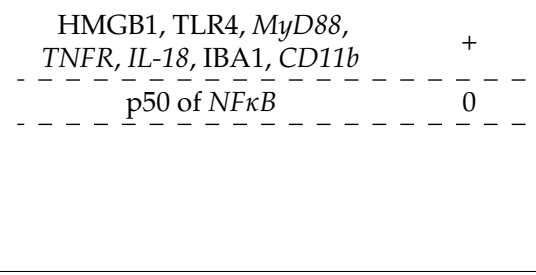 & $\begin{array}{l} \\
----- \\
----- \\
\text { CORT113176 }\end{array}$ & 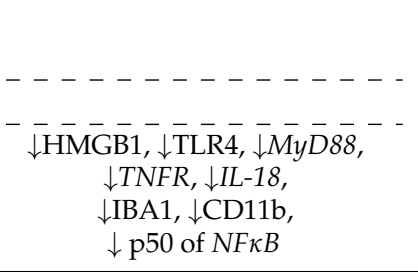 & IHC, RT-PCR & $\begin{array}{c}------ \\
----- \\
\uparrow\end{array}$ & [47] \\
\hline Wr mouse & $\mathrm{NFR} / \mathrm{wr}$ & P150 & spinal cord & 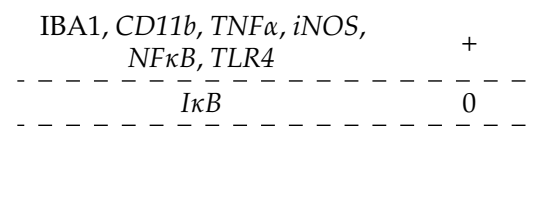 & $\begin{array}{c} \\
------ \\
----- \\
\text { nestorone }\end{array}$ & 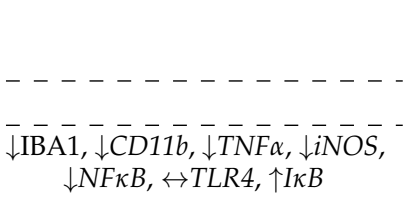 & IHC, RT-PCR & $\begin{array}{c} \\
------ \\
----- \\
\uparrow\end{array}$ & [48] \\
\hline
\end{tabular}

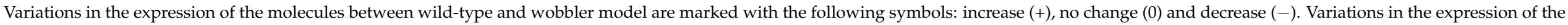

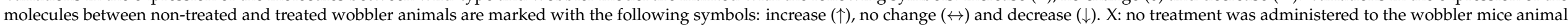

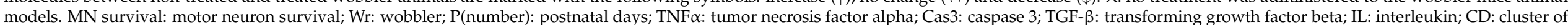

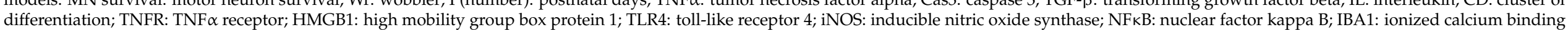

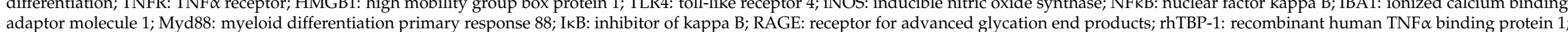
IF: immunofluorescence staining; RT-PCR: reverse transcription polymerase chain reaction; IHC: immunohistochemistry. 


\subsection{Summary of the Microglial Characteristics of the Wobbler Mouse}

Considered as an sALS animal model, wobbler mice have a mutated Vps54 gene. This mutation causes defects in the cellular transportation system, which eventually leads to neurobehavioral abnormalities in wobbler mice, mimicking ALS symptoms. Wobbler mice having a C57BL/6J background showed increased levels of M1-type markers in the motor cortex and cerebellum. Similarly, wobbler mice on the NFR background exhibited elevated levels of M1-type cytokines in the spinal cord. Because most studies have focused on M1type markers, unfortunately, there are only a few studies investigating M2-type cytokines in wobbler mice. However, the histological and neurological outcomes of wobbler mice bring to mind the fact that neurodegenerative cytokines released by microglia overweigh the neuroprotective ones, which ultimately exacerbates the disease starting from the early clinical stage.

There have been several in vivo studies examining the effects of different treatments of wobbler mice on microglial function. Of these, the administration of neuroactive steroids such as progesterone, nestorone and CORT113176 diminished microgliosis and enhanced motor neuron survival in wobbler mice, acting through the NFKB signaling pathway. On the other hand, another steroid, norethindrone, failed to prevent the expression of neurodegenerative cytokines and therefore could not augment the motor neuron survival. Additionally, treatment of wobbler mice with rhTBP-1, an inhibitor of $\operatorname{Tnf} \alpha$, failed to change the expressions of either Tnf $\alpha$ or TNFR, even though it enhanced the motor neuron viability.

\section{Conclusions}

ALS is a fatal neurodegenerative disease. To date, numerous animal models have been generated to investigate the ALS disease in vivo. ALS is characterized by neuroinflammation in the CNS tissue of both patients and animal models. Together with motor neuron degeneration, microglia are activated in ALS and transform into an amoeboid shape. In a very simplified way, we can then refer to these processes as M1-type activation, where microglia release toxic proinflammatory agents, or M2-type activation, where microglia produce neuroprotective anti-inflammatory factors. The balance between M1 and M2 activation states is broken down during the course of ALS progression and M1-type activation can further exacerbate the disease. Many promising preclinical studies in some ALS models have shown that targeting the prevalent neuroinflammation has resulted in a slowing of symptoms, as well as reduced neurodegeneration. Unfortunately, however, transformation of these treatments into clinical trials has been unsuccessful. One possible reason for this is the strong heterogeneity of the causes of the disease. Our research has shown that of the four ALS mouse models considered here, only two models, SOD1 and wobbler, have been adequately studied with respect to neuroinflammation. Thus, the understanding of the role of microglia in the comparison between different models is still lacking. It has also been noticed that most of the studies deal with a pre-symptomatic or an early stage of onset of the disease. It must be considered that it will not be possible to treat future ALS-diagnosed patients before the onset or even directly at the onset of symptoms. These would be possible explanations for the failure of translation from preclinical to clinical investigations. Furthermore, the aspect of intracellular communication should be considered. Since all cell types of an ALS model have a genetic abnormality, affecting the functionality of these cells individually, it must be considered that the activity of microglia can also be affected by these cells of different backgrounds in different ways.

Neuroinflammation plays an essential role in all ALS patients. Due to the heterogeneity of the disease, it is mandatory to investigate the diverse roles of microglia, as reviewed by Cipollina et al., 2020, in many different models of ALS [110]. After all, this is the basis for finding an appropriate therapy for different ALS cohorts.

Author Contributions: H.C., C.T. and V.M. performed literature research and wrote the original manuscript draft. H.C. and V.M. made the figures. All authors have read and agreed to the published version of the manuscript. 
Funding: This research received no external funding.

Acknowledgments: This study was supported by German Academic Exchange Service to Hilal Cihankaya. We acknowledge support by the Open Access Publication Funds of the Ruhr University Bochum. Graphical art in graphical abstract was prepare using (with modifications) Smart Servier Medical Art (https:/ / smart.servier.com/) by Servier (Suresnes, France) licensed under a Creative Commons Attribution 3.0 Unported License (https:/ / creativecommons.org/licenses/by/3.0/).

Conflicts of Interest: The authors declare no conflict of interest.

\begin{tabular}{|c|c|}
\hline 1700112E06Rik & Leucine rich melanocyte differentiation associated protein \\
\hline $5 \mathrm{D} 4$ & Keratan sulfate \\
\hline ALS & Amyotrophic lateral sclerosis \\
\hline APOE & Apolipoprotein E \\
\hline Arg1 & Arginase 1 \\
\hline Asc & Apoptosis associated speck-like protein containing a CARD \\
\hline ASIALO-EPO & Asialo erythropoietin \\
\hline Axl & Tyrosine protein kinase receptor UFO \\
\hline BDNF & Brain derived neurotrophic factor \\
\hline Brca1 & Breast cancer gene 1 \\
\hline $\mathrm{C} 1 \mathrm{q}$ & Complement component $1 \mathrm{q}$ \\
\hline $\mathrm{C} 1 \mathrm{qB}$ & C1q beta polypeptide \\
\hline $\mathrm{C} 3$ & Complement component 3 \\
\hline $\mathrm{C} 5 \mathrm{a}$ & Complement component $5 \mathrm{a}$ \\
\hline C5aR1 & C5a receptor 1 \\
\hline C9Orf72 & Chromosome 9 open reading frame 72 \\
\hline Camk2b & Calcium/calmodulin dependent protein kinase beta 2 \\
\hline Cas & Caspase \\
\hline CCL & $\mathrm{C}-\mathrm{C}$ motif chemokine ligand \\
\hline $\mathrm{CD}$ & Cluster of differentiation \\
\hline CD11b & Cluster of differentiation molecule $11 b$ \\
\hline CD55 & Complement regulator \\
\hline CD59a & Complement regulator \\
\hline Cebpa & CCAAT/enhancer binding protein \\
\hline CEPO & Asialo erythropoietin \\
\hline CEPO & Carbamylated erythropoietin \\
\hline Clec7a & C-type lectin domain containing 7A \\
\hline CNS & Central nervous system \\
\hline $\mathrm{COX} 2$ & Cyclo-oxygenase 2 \\
\hline Csf1 & Colony stimulating factor 1 \\
\hline CX3CR1 & C-X3-C motif chemokine receptor 1 \\
\hline Cyr61 & Cysteine rich angiogenic inducer 61 \\
\hline $\mathrm{EPO}$ & Erythropoietin \\
\hline fALS & Familial amyotrophic lateral sclerosis \\
\hline $\mathrm{fB}$ & Complement factor B \\
\hline Fizz1 & Found in inflammatory zone 1 \\
\hline FUS & Fused in sarcoma \\
\hline Gadd45a & Growth arrest and DNA damage inducible protein \\
\hline GARP & Golgi-associated retrograde protein \\
\hline GDNF & Glial cell line derived neurotrophic factor \\
\hline Grn & Granulin \\
\hline Hexb & Hexosaminidase subunit beta \\
\hline HMGB1 & High mobility group box protein 1 \\
\hline HuR & ELAV-like RNA binding protein 1 \\
\hline $\mathrm{I} \kappa \mathrm{B}$ & Inhibitor of kappa B \\
\hline IBA1 & Ionized calcium binding adaptor molecule 1 \\
\hline
\end{tabular}




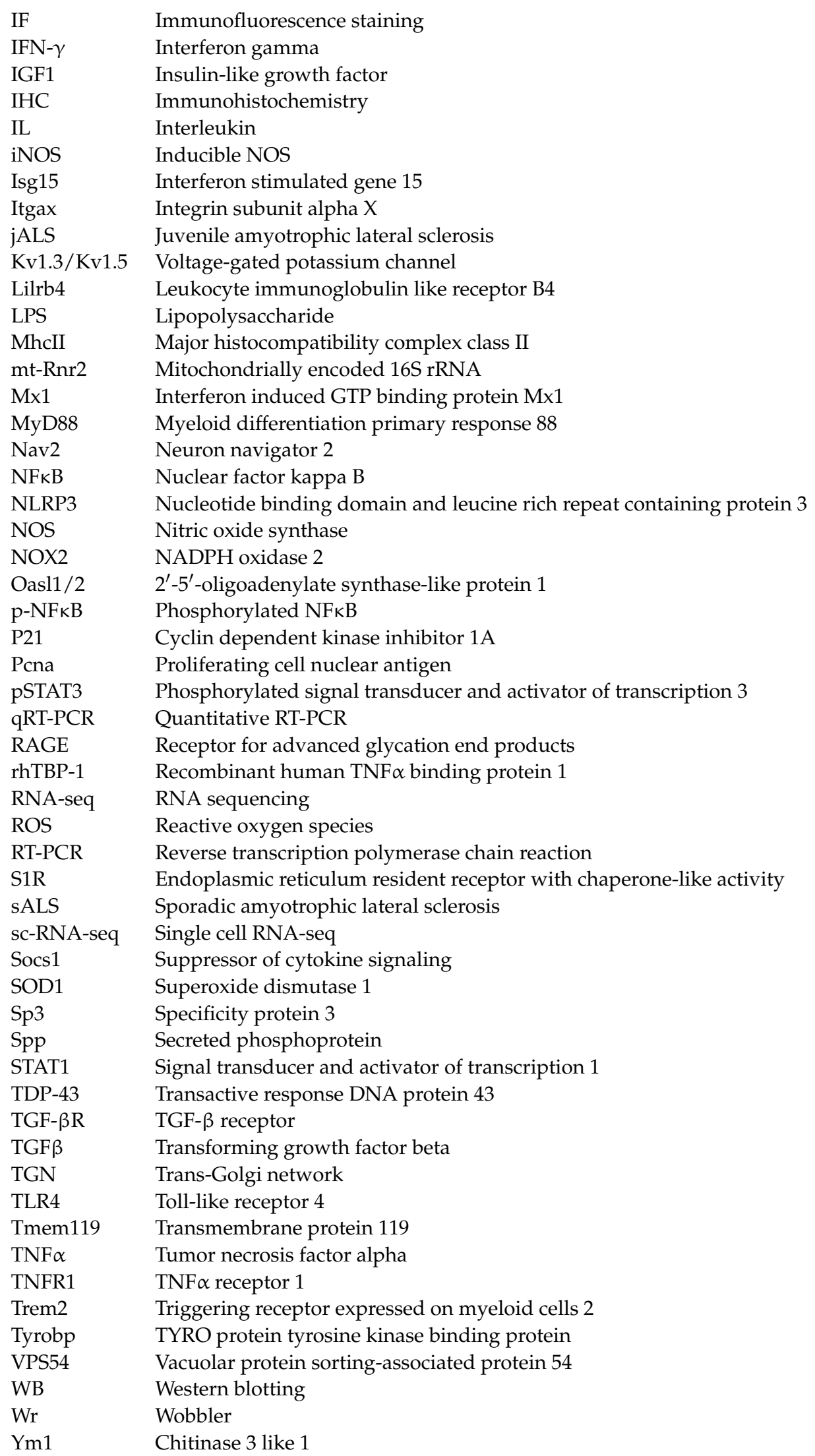




\section{References}

1. Ferraiuolo, L.; Kirby, J.; Grierson, A.J.; Sendtner, M.; Shaw, P.J. Molecular Pathways of Motor Neuron Injury in Amyotrophic Lateral Sclerosis. Nat. Rev. Neurol. 2011, 7, 616-630. [CrossRef] [PubMed]

2. Robberecht, W.; Philips, T. The Changing Scene of Amyotrophic Lateral Sclerosis. Nat. Rev. Neurosci. 2013. [CrossRef] [PubMed]

3. Bruijn, L.I.; Miller, T.M.; Cleveland, D.W. Unraveling the Mechanisms Involved in Motor Neuron Degeneration in Als. Annu. Rev. Neurosci. 2004, 14, 248-264. [CrossRef]

4. Philips, T.; Rothstein, J.D. Glial Cells in Amyotrophic Lateral Sclerosis. Exp. Neurol. 2014, 262, 111-120. [CrossRef]

5. Polazzi, E.; Monti, B. Microglia and Neuroprotection: From in Vitro Studies to Therapeutic Applications. Prog. Neurobiol. 2010, 92, 293-315. [CrossRef]

6. Imai, Y.; Kohsaka, S. Intracellular Signaling in M-CSF-Induced Microglia Activation: Role of Iba1. Glia 2002, 40, 164-174. [CrossRef] [PubMed]

7. Panni, R.Z.; Herndon, J.M.; Zuo, C.; Hegde, S.; Hogg, G.D.; Knolhoff, B.L.; Breden, M.A.; Li, X.; Krisnawan, V.E.; Khan, S.Q.; et al. Agonism of CD11b Reprograms Innate Immunity to Sensitize Pancreatic Cancer to Immunotherapies. Sci. Transl. Med. 2019, 11, 499. [CrossRef]

8. Chistiakov, D.A.; Killingsworth, M.C.; Myasoedova, V.A.; Orekhov, A.N.; Bobryshev, Y.V. CD68/Macrosialin: Not Just a Histochemical Marker. Lab. Investig. 2017, 97, 4-12. [CrossRef]

9. Silverstein, R.L.; Febbraio, M. CD36, a Scavenger Receptor Involved in Immunity, Metabolism, Angiogenesis, and Behavior. Sci. Signal. 2009, 2. [CrossRef]

10. Benveniste, E.N.; Nguyen, V.T.; Wesemann, D.R. Molecular Regulation of CD40 Gene Expression in Macrophages and Microglia. Brain Behav. Immun. 2004, 18, 7-12. [CrossRef]

11. Cunha, C.; Santos, C.; Gomes, C.; Fernandes, A.; Correia, A.M.; Sebastião, A.M.; Vaz, A.R.; Brites, D. Downregulated Glia Interplay and Increased MiRNA-155 as Promising Markers to Track ALS at an Early Stage. Mol. Neurobiol. 2018, 55, $4207-4224$. [CrossRef] [PubMed]

12. Johann, S.; Heitzer, M.; Kanagaratnam, M.; Goswami, A.; Rizo, T.; Weis, J.; Troost, D.; Beyer, C. NLRP3 Inflammasome Is Expressed by Astrocytes in the SOD1 Mouse Model of ALS and in Human Sporadic ALS Patients. Glia 2015, 63, $2260-2273$. [CrossRef] [PubMed]

13. Maniatis, S.; Äijö, T.; Vickovic, S.; Braine, C.; Kang, K.; Mollbrink, A.; Fagegaltier, D.; Andrusivová, Ž.; Saarenpää, S.; Saiz-Castro, G.; et al. Spatiotemporal Dynamics of Molecular Pathology in Amyotrophic Lateral Sclerosis. Science 2019, 364, 89-93. [CrossRef] [PubMed]

14. Chiarotto, G.B.; Cartarozzi, L.P.; Perez, M.; Biscola, N.P.; Spejo, A.B.; Gubert, F.; Franca Junior, M.; Mendez-Otero, R.; De Oliveira, A.L.R. Tempol Improves Neuroinflammation and Delays Motor Dysfunction in a Mouse Model (SOD1G93A) of ALS. J. Neuroinflamm. 2019, 16. [CrossRef] [PubMed]

15. Romer, S.H.; Seedle, K.; Turner, S.M.; Li, J.; Baccei, M.L.; Crone, S.A. Accessory Respiratory Muscles Enhance Ventilation in ALS Model Mice and Are Activated by Excitatory V2a Neurons. Exp. Neurol. 2017, 287, 192-204. [CrossRef]

16. Bonifacino, T.; Cattaneo, L.; Gallia, E.; Puliti, A.; Melone, M.; Provenzano, F.; Bossi, S.; Musante, I.; Usai, C.; Conti, F.; et al. In-Vivo Effects of Knocking-down Metabotropic Glutamate Receptor 5 in the SOD1G93A Mouse Model of Amyotrophic Lateral Sclerosis. Neuropharmacology 2017, 123, 433-445. [CrossRef]

17. Ringer, C.; Weihe, E.; Schütz, B. SOD1G93A Mutant Mice Develop a Neuroinflammation-Independent Dendropathy in Excitatory Neuronal Subsets of the Olfactory Bulb and Retina. J. Neuropathol. Exp. Neurol. 2017, 76, 769-778. [CrossRef]

18. Kook, M.G.; Choi, S.W.; Seo, Y.; Kim, D.W.; Song, B.K.; Son, I.; Kim, S.; Kang, K.S. KCHO-1, a Novel Herbal Anti-Inflammatory Compound, Attenuates Oxidative Stress in an Animal Model of Amyotrophic Lateral Sclerosis. J. Vet. Sci. $2017,18,487-497$. [CrossRef]

19. Sereddenina, T.; Nayernia, Z.; Sorce, S.; Maghzal, G.J.; Filippova, A.; Ling, S.-C.; Basset, O.; Plastre, O.; Daali, Y.; Rushing, E.J.; et al. Evaluation of NADPH Oxidases as Drug Targets in a Mouse Model of Familial Amyotrophic Lateral Sclerosis. Free Radic. Biol. Med. 2016, 97, 95-108. [CrossRef]

20. Sheean, R.K.; McKay, F.C.; Cretney, E.; Bye, C.R.; Perera, N.D.; Tomas, D.; Weston, R.A.; Scheller, K.J.; Djouma, E.; Menon, P.; et al. Association of Regulatory T-Cell Expansion with Progression of Amyotrophic Lateral Sclerosis. JAMA Neurol. 2018, 75, 681. [CrossRef]

21. Solomonov, Y.; Hadad, N.; Levy, R. Reduction of Cytosolic Phospholipase A2 $\alpha$ Upregulation Delays the Onset of Symptoms in SOD1G93A Mouse Model of Amyotrophic Lateral Sclerosis. J. Neuroinflamm. 2016, 13, 134. [CrossRef] [PubMed]

22. Rabinovich-Nikitin, I.; Ezra, A.; Barbiro, B.; Rabinovich-Toidman, P.; Solomon, B. Chronic Administration of AMD3100 Increases Survival and Alleviates Pathology in SOD1G93A Mice Model of ALS. J. Neuroinflamm. 2016, 13, 1. [CrossRef] [PubMed]

23. Cocozza, G.; di Castro, M.A.; Carbonari, L.; Grimaldi, A.; Antonangeli, F.; Garofalo, S.; Porzia, A.; Madonna, M.; Mainiero, F.; Santoni, A.; et al. $\mathrm{Ca}^{2+}$-Activated $\mathrm{K}^{+}$Channels Modulate Microglia Affecting Motor Neuron Survival in HSOD1 G93A Mice. Brain Behav. Immun. 2018, 73, 584-595. [CrossRef] [PubMed]

24. Apolloni, S.; Fabbrizio, P.; Amadio, S.; Volonte, C. Actions of the Antihistaminergic Clemastine on Presymptomatic SOD1-G93A Mice Ameliorate ALS Disease Progression. J. Neuroinflamm. 2016, 13, 191. [CrossRef] [PubMed] 
25. Korhonen, P.; Pollari, E.; Kanninen, K.M.; Savchenko, E.; Lehtonen, Š.; Wojciechowski, S.; Pomeshchik, Y.; Van Den Bosch, L.; Goldsteins, G.; Koistinaho, J.; et al. Long-Term Interleukin-33 Treatment Delays Disease Onset and Alleviates Astrocytic Activation in a Transgenic Mouse Model of Amyotrophic Lateral Sclerosis. IBRO Rep. 2019, 6, 74-86. [CrossRef]

26. Zeldich, E.; Di Chen, C.; Boden, E.; Howat, B.; Nasse, J.S.; Zeldich, D.; Lambert, A.G.; Yuste, A.; Cherry, J.D.; Mathias, R.M.; et al. Klotho Is Neuroprotective in the Superoxide Dismutase (SOD1G93A) Mouse Model of ALS. J. Mol. Neurosci. 2019, 69, $264-285$. [CrossRef]

27. El Oussini, H.; Bayer, H.; Scekic-Zahirovic, J.; Vercruysse, P.; Sinniger, J.; Dirrig-Grosch, S.; Dieterlé, S.; Echaniz-Laguna, A.; Larmet, Y.; Müller, K.; et al. Serotonin 2B Receptor Slows Disease Progression and Prevents Degeneration of Spinal Cord Mononuclear Phagocytes in Amyotrophic Lateral Sclerosis. Acta Neuropathol. 2016, 131, 465-480. [CrossRef]

28. Cai, M.D.; Yang, E.J. Gamisoyo-San Ameliorates Neuroinflammation in the Spinal Cord of HSOD1G93A Transgenic Mice. Mediat. Inflamm. 2018. [CrossRef]

29. Fellner, A.; Barhum, Y.; Angel, A.; Perets, N.; Steiner, I.; Offen, D.; Lev, N. Toll-Like Receptor-4 Inhibitor TAK-242 Attenuates Motor Dysfunction and Spinal Cord Pathology in an Amyotrophic Lateral Sclerosis Mouse Model. Int. J. Mol. Sci. 2017, 18, 1666. [CrossRef]

30. Matsye, P.; Zheng, L.; Si, Y.; Kim, S.; Luo, W.; Crossman, D.K.; Bratcher, P.E.; King, P.H. HuR Promotes the Molecular Signature and Phenotype of Activated Microglia: Implications for Amyotrophic Lateral Sclerosis and Other Neurodegenerative Diseases. Glia 2017, 65, 945-963. [CrossRef]

31. LaClair, K.D.; Zhou, Q.; Michaelsen, M.; Wefers, B.; Brill, M.S.; Janjic, A.; Rathkolb, B.; Farny, D.; Cygan, M.; de Angelis, M.H.; et al. Congenic Expression of Poly-GA but Not Poly-PR in Mice Triggers Selective Neuron Loss and Interferon Responses Found in C9orf72 ALS. Acta Neuropathol. 2020, 140, 121-142. [CrossRef] [PubMed]

32. Schludi, M.H.; Becker, L.; Garrett, L.; Gendron, T.F.; Zhou, Q.; Schreiber, F.; Popper, B.; Dimou, L.; Strom, T.M.; Winkelmann, J.; et al. Spinal Poly-GA Inclusions in a C9orf72 Mouse Model Trigger Motor Deficits and Inflammation without Neuron Loss. Acta Neuropathol. 2017, 134, 241-254. [CrossRef]

33. Zhou, Q.; Mareljic, N.; Michaelsen, M.; Parhizkar, S.; Heindl, S.; Nuscher, B.; Farny, D.; Czuppa, M.; Schludi, C.; Graf, A.; et al. Active Poly-GA Vaccination Prevents Microglia Activation and Motor Deficits in a C9orf72 Mouse Model. EMBO Mol. Med. 2020, 12. [CrossRef] [PubMed]

34. Zhang, Y.J.; Gendron, T.F.; Ebbert, M.T.W.; O’Raw, A.D.; Yue, M.; Jansen-West, K.; Zhang, X.; Prudencio, M.; Chew, J.; Cook, C.N.; et al. Poly(GR) Impairs Protein Translation and Stress Granule Dynamics in C9orf72-Associated Frontotemporal Dementia and Amyotrophic Lateral Sclerosis. Nat. Med. 2018, 24, 1136-1142. [CrossRef] [PubMed]

35. Lee, J.D.; Levin, S.C.; Willis, E.F.; Li, R.; Woodruff, T.M.; Noakes, P.G. Complement Components Are Upregulated and Correlate with Disease Progression in the TDP-43 Q331K Mouse Model of Amyotrophic Lateral Sclerosis. J. Neuroinflamm. 2018, 15. [CrossRef] [PubMed]

36. Jara, J.H.; Gautam, M.; Kocak, N.; Xie, E.F.; Mao, Q.; Bigio, E.H.; Özdinler, P.H. MCP1-CCR2 and Neuroinflammation in the ALS Motor Cortex with TDP-43 Pathology. J. Neuroinflamm. 2019, 16, 196. [CrossRef] [PubMed]

37. Perera, N.D.; Sheean, R.K.; Crouch, P.J.; White, A.R.; Horne, M.K.; Turner, B.J. Enhancing Survival Motor Neuron Expression Extends Lifespan and Attenuates Neurodegeneration in Mutant TDP-43 Mice. Hum. Mol. Genet. 2016, 25, 4080-4093. [CrossRef]

38. Dahlke, C.; Saberi, D.; Ott, B.; Brand-Saberi, B.; Schmitt-John, T.; Theiss, C. Inflammation and Neuronal Death in the Motor Cortex of the Wobbler Mouse, an ALS Animal Model. J. Neuroinflamm. 2015, 12. [CrossRef]

39. Saberi, D.; Ott, B.; Dahlke, C.; Matschke, V.; Schmitt-John, T.; Theiss, C. The Spatiotemporal Pattern of Degeneration in the Cerebellum of the Wobbler Mouse. J. Neuropathol. Exp. Neurol. 2016, 75, 347-357. [CrossRef]

40. Bigini, P.; Repici, M.; Cantarella, G.; Fumagalli, E.; Barbera, S.; Cagnotto, A.; De Luigi, A.; Tonelli, R.; Bernardini, R.; Borsello, T.; et al. Recombinant Human TNF-Binding Protein-1 (RhTBP-1) Treatment Delays Both Symptoms Progression and Motor Neuron Loss in the Wobbler Mouse. Neurobiol. Dis. 2008, 29, 465-476. [CrossRef]

41. Peviani, M.; Salvaneschi, E.; Bontempi, L.; Petese, A.; Manzo, A.; Rossi, D.; Salmona, M.; Collina, S.; Bigini, P.; Curti, D. Neuroprotective Effects of the Sigma-1 Receptor (S1R) Agonist PRE-084, in a Mouse Model of Motor Neuron Disease Not Linked to SOD1 Mutation. Neurobiol. Dis. 2014, 62, 218-232. [CrossRef] [PubMed]

42. Gargiulo-Monachelli, G.; Meyer, M.; Lara, A.; Garay, L.; Lima, A.; Roig, P.; De Nicola, A.F.; Gonzalez Deniselle, M.C. Comparative Effects of Progesterone and the Synthetic Progestin Norethindrone on Neuroprotection in a Model of Spontaneous Motoneuron Degeneration. J. Steroid Biochem. Mol. Biol. 2019, 192. [CrossRef] [PubMed]

43. De Paola, M.; Mariani, A.; Bigini, P.; Peviani, M.; Ferrara, G.; Molteni, M.; Gemma, S.; Veglianese, P.; Castellaneta, V.; Boldrin, V.; et al. Neuroprotective Effects of Toll-like Receptor 4 Antagonism in Spinal Cord Cultures and in a Mouse Model of Motor Neuron Degeneration. Mol. Med. 2012, 18, 971-981. [CrossRef]

44. Mennini, T.; De Paola, M.; Bigini, P.; Mastrotto, C.; Fumagalli, E.; Barbera, S.; Mengozzi, M.; Viviani, B.; Corsini, E.; Marinovich, M.; et al. Nonhematopoietic Erythropoietin Derivatives Prevent Motoneuron Degeneration in Vitro and in Vivo. Mol. Med. 2006, 12, 153-160. [CrossRef] [PubMed]

45. Meyer, M.; Gonzalez Deniselle, M.C.; Hunt, H.; De Kloet, E.R.; De Nicola, A.F. The Selective Glucocorticoid Receptor Modulator CORT108297 Restores Faulty Hippocampal Parameters in Wobbler and Corticosterone-Treated Mice. J. Steroid Biochem. Mol. Biol. 2014, 143, 40-48. [CrossRef] [PubMed] 
46. Meyer, M.; Lara, A.; Hunt, H.; Belanoff, J.; de Kloet, E.R.; Gonzalez Deniselle, M.C.; De Nicola, A.F. The Selective Glucocorticoid Receptor Modulator Cort 113176 Reduces Neurodegeneration and Neuroinflammation in Wobbler Mice Spinal Cord. Neuroscience 2018, 384, 384-396. [CrossRef]

47. Meyer, M.; Kruse, M.S.; Garay, L.; Lima, A.; Roig, P.; Hunt, H.; Belanoff, J.; de Kloet, E.R.; Deniselle, M.C.G.; De Nicola, A.F. Long-Term Effects of the Glucocorticoid Receptor Modulator CORT113176 in Murine Motoneuron Degeneration. Brain Res. 2020, 1727. [CrossRef]

48. Meyer, M.; Gonzalez Deniselle, M.C.; Garay, L.; Sitruk-Ware, R.; Guennoun, R.; Schumacher, M.; De Nicola, A.F. The Progesterone Receptor Agonist Nestorone Holds Back Proinflammatory Mediators and Neuropathology in the Wobbler Mouse Model of Motoneuron Degeneration. Neuroscience 2015, 308, 51-63. [CrossRef]

49. Ransohoff, R.M. A Polarizing Question: Do M1 and M2 Microglia Exist. Nat. Neurosci. 2016, 19, 987-991. [CrossRef]

50. Kabba, J.A.; Xu, Y.; Christian, H.; Ruan, W.; Chenai, K.; Xiang, Y.; Zhang, L.; Saavedra, J.M.; Pang, T. Microglia: Housekeeper of the Central Nervous System. Cell. Mol. Neurobiol. 2018, 38, 53-71. [CrossRef]

51. Zhao, W.; Beers, D.R.; Appel, S.H. Immune-Mediated Mechanisms in the Pathoprogression of Amyotrophic Lateral Sclerosis. J. Neuroimmune Pharmacol. 2013, 8, 888-899. [CrossRef]

52. Henkel, J.S.; Engelhardt, J.I.; Siklós, L.; Simpson, E.P.; Kim, S.H.; Pan, T.; Goodman, J.C.; Siddique, T.; Beers, D.R.; Appel, S.H. Presence of Dendritic Cells, MCP-1, and Activated Microglia/Macrophages in Amyotrophic Lateral Sclerosis Spinal Cord Tissue. Ann. Neurol. 2004, 55, 221-235. [CrossRef] [PubMed]

53. Corcia, P.; Tauber, C.; Vercoullie, J.; Arlicot, N.; Prunier, C.; Praline, J.; Nicolas, G.; Venel, Y.; Hommet, C.; Baulieu, J.L.; et al. Molecular Imaging of Microglial Activation in Amyotrophic Lateral Sclerosis. PLoS ONE 2012, 7. [CrossRef] [PubMed]

54. Turner, M.R.; Cagnin, A.; Turkheimer, F.E.; Miller, C.C.J.; Shaw, C.E.; Brooks, D.J.; Leigh, P.N.; Banati, R.B. Evidence of Widespread Cerebral Microglial Activation in Amyotrophic Lateral Sclerosis: An [11C](R)-PK11195 Positron Emission Tomography Study. Neurobiol. Dis. 2004, 15, 601-609. [CrossRef] [PubMed]

55. Evans, M.C.; Couch, Y.; Sibson, N.; Turner, M.R. Inflammation and Neurovascular Changes in Amyotrophic Lateral Sclerosis. Mol. Cell. Neurosci. 2013, 53, 34-41. [CrossRef] [PubMed]

56. Lewis, C.A.; Manning, J.; Rossi, F.; Krieger, C. The Neuroinflammatory Response in ALS: The Roles of Microglia and T Cells. Neurol. Res. Int. 2012. [CrossRef] [PubMed]

57. Santiago, A.R.; Bernardino, L.; Agudo-Barriuso, M.; Gonçalves, J. Microglia in Health and Disease: A Double-Edged Sword. Mediat. Inflamm. 2017. [CrossRef]

58. Liu, J.; Wang, F. Role of Neuroinflammation in Amyotrophic Lateral Sclerosis: Cellular Mechanisms and Therapeutic Implications. Front. Immunol. 2017, 8. [CrossRef]

59. Al-Chalabi, A.; Van Den Berg, L.H.; Veldink, J. Gene Discovery in Amyotrophic Lateral Sclerosis: Implications for Clinical Management. Nat. Rev. Neurol. 2017, 13, 96-104. [CrossRef]

60. Zou, Z.Y.; Zhou, Z.R.; Che, C.H.; Liu, C.Y.; He, R.L.; Huang, H.P. Genetic Epidemiology of Amyotrophic Lateral Sclerosis: A Systematic Review and Meta-Analysis. J. Neurol. Neurosurg. Psychiatry 2017, 88, 540-549. [CrossRef]

61. Bosco, D.A.; Morfini, G.; Karabacak, N.M.; Song, Y.; Gros-Louis, F.; Pasinelli, P.; Goolsby, H.; Fontaine, B.A.; Lemay, N.; McKennaYasek, D.; et al. Wild-Type and Mutant SOD1 Share an Aberrant Conformation and a Common Pathogenic Pathway in ALS. Nat. Neurosci. 2010, 13, 1396-1403. [CrossRef] [PubMed]

62. Allen, S.; Heath, P.R.; Kirby, J.; Wharton, S.B.; Cookson, M.R.; Menzies, F.M.; Banks, R.E.; Shaw, P.J. Analysis of the Cytosolic Proteome in a Cell Culture Model of Familial Amyotrophic Lateral Sclerosis Reveals Alterations to the Proteasome, Antioxidant Defenses, and Nitric Oxide Synthetic Pathways. J. Biol. Chem. 2003, 278, 6371-6383. [CrossRef] [PubMed]

63. Heiman-Patterson, T.D.; Sher, R.B.; Blankenhorn, E.A.; Alexander, G.; Deitch, J.S.; Kunst, C.B.; Maragakis, N.; Cox, G. Effect of Genetic Background on Phenotype Variability in Transgenic Mouse Models of Amyotrophic Lateral Sclerosis: A Window of Opportunity in the Search for Genetic Modifiers. Amyotroph. Lateral Scler. 2011, 12, 79-86. [CrossRef] [PubMed]

64. Nardo, G.; Trolese, M.C.; Tortarolo, M.; Vallarola, A.; Freschi, M.; Pasetto, L.; Bonetto, V.; Bendotti, C. New Insights on the Mechanisms of Disease Course Variability in ALS from Mutant SOD1 Mouse Models. Brain Pathol. 2016, 26, 237-247. [CrossRef] [PubMed]

65. Nardo, G.; Trolese, M.C.; de Vito, G.; Cecchi, R.; Riva, N.; Dina, G.; Heath, P.R.; Quattrini, A.; Shaw, P.J.; Piazza, V.; et al. Immune Response in Peripheral Axons Delays Disease Progression in SOD1G93A Mice. J. Neuroinflamm. 2016, 13. [CrossRef]

66. Marino, M.; Papa, S.; Crippa, V.; Nardo, G.; Peviani, M.; Cheroni, C.; Trolese, M.C.; Lauranzano, E.; Bonetto, V.; Poletti, A.; et al. Differences in Protein Quality Control Correlate with Phenotype Variability in 2 Mouse Models of Familial Amyotrophic Lateral Sclerosis. Neurobiol. Aging 2015, 36, 492-504. [CrossRef]

67. Turner, B.J.; Talbot, K. Transgenics, Toxicity and Therapeutics in Rodent Models of Mutant SOD1-Mediated Familial ALS. Prog. Neurobiol. 2008, 85, 94-134. [CrossRef]

68. Gurney, M.E.; Pu, H.; Chiu, A.Y.; Dal Canto, M.C.; Polchow, C.Y.; Alexander, D.D.; Caliendo, J.; Hentati, A.; Kwon, Y.W.; Deng, H.X.; et al. Motor Neuron Degeneration in Mice That Express a Human Cu, Zn Superoxide Dismutase Mutation. Science 1994, 264, 1772-1775. [CrossRef]

69. Foyez, T.; Takeda-Uchimura, Y.; Ishigaki, S.; Narentuya, N.; Zhang, Z.; Sobue, G.; Kadomatsu, K.; Uchimura, K. Microglial Keratan Sulfate Epitope Elicits in Central Nervous Tissues of Transgenic Model Mice and Patients with Amyotrophic Lateral Sclerosis. Am. J. Pathol. 2015, 185, 3053-3065. [CrossRef] 
70. Ohgomori, T.; Yamasaki, R.; Takeuchi, H.; Kadomatsu, K.; Kira, J.I.; Jinno, S. Differential Activation of Neuronal and Glial STAT3 in the Spinal Cord of the SOD1G93A Mouse Model of Amyotrophic Lateral Sclerosis. Eur. J. Neurosci. 2017, 46, 2001-2014. [CrossRef]

71. Mitsui, S.; Otomo, A.; Nozaki, M.; Ono, S.; Sato, K.; Shirakawa, R.; Adachi, H.; Aoki, M.; Sobue, G.; Shang, H.F.; et al. Systemic Overexpression of SQSTM1/P62 Accelerates Disease Onset in a SOD1H46R-Expressing ALS Mouse Model. Mol. Brain 2018, 11. [CrossRef] [PubMed]

72. Trias, E.; Ibarburu, S.; Barreto-Núñez, R.; Babdor, J.; Maciel, T.T.; Guillo, M.; Gros, L.; Dubreuil, P.; Díaz-Amarilla, P.; Cassina, P.; et al. Post-Paralysis Tyrosine Kinase Inhibition with Masitinib Abrogates Neuroinflammation and Slows Disease Progression in Inherited Amyotrophic Lateral Sclerosis. J. Neuroinflamm. 2016, 13. [CrossRef]

73. Deora, V.; Lee, J.D.; Albornoz, E.A.; McAlary, L.; Jagaraj, C.J.; Robertson, A.A.B.; Atkin, J.D.; Cooper, M.A.; Schroder, K.; Yerbury, J.J.; et al. The Microglial NLRP3 Inflammasome Is Activated by Amyotrophic Lateral Sclerosis Proteins. Glia 2020, 68, 407-421. [CrossRef] [PubMed]

74. Silverman, J.M.; Christy, D.; Shyu, C.C.; Moon, K.M.; Fernando, S.; Gidden, Z.; Cowan, C.M.; Ban, Y.; Greg Stacey, R.; Grad, L.I.; et al. CNS-Derived Extracellular Vesicles from Superoxide Dismutase 1 (SOD1)G93A ALS Mice Originate from Astrocytes and Neurons and Carry Misfolded SOD1. J. Biol. Chem. 2019, 294, 3744-3759. [CrossRef] [PubMed]

75. Kassa, R.M.; Bonafede, R.; Boschi, F.; Bentivoglio, M.; Mariotti, R. Effect of Physical Exercise and Anabolic Steroid Treatment on Spinal Motoneurons and Surrounding Glia of Wild-Type and ALS Mice. Brain Res. 2017, 1657, 269-278. [CrossRef] [PubMed]

76. Zhang, J.; Liu, Y.; Liu, X.; Li, S.; Cheng, C.; Chen, S.; Le, W. Dynamic Changes of CX3CL1/CX3CR1 Axis during Microglial Activation and Motor Neuron Loss in the Spinal Cord of ALS Mouse Model. Transl. Neurodegener. 2018, 7. [CrossRef]

77. Zhang, J.; Liang, H.; Zhu, L.; Gan, W.; Tang, C.; Li, J.; Xu, R. Expression and Distribution of Arylsulfatase B Are Closely Associated with Neuron Death in SOD1 G93A Transgenic Mice. Mol. Neurobiol. 2018, 55, 1323-1337. [CrossRef]

78. Shijo, T.; Warita, H.; Suzuki, N.; Ikeda, K.; Mitsuzawa, S.; Akiyama, T.; Ono, H.; Nishiyama, A.; Izumi, R.; Kitajima, Y.; et al. Antagonizing Bone Morphogenetic Protein 4 Attenuates Disease Progression in a Rat Model of Amyotrophic Lateral Sclerosis. Exp. Neurol. 2018, 307, 164-179. [CrossRef]

79. Han, G.; Li, F.; Singh, T.P.; Wolf, P.; Wang, X.J. The Pro-Inflammatory Role of TGFß1: A Paradox? Int. J. Biol. Sci. 2012, 8, 28-235. [CrossRef]

80. Epperly, M.W.; Fisher, R.; Rigatti, L.; Watkins, S.; Zhang, X.; Hou, W.; Shields, D.; Franicola, D.; Bayir, H.; Wang, H.; et al. Amelioration of Amyotrophic Lateral Sclerosis in SOD1G93A Mice by M2 Microglia from Transplanted Marrow. In Vivo 2019, 33, 675-688. [CrossRef]

81. Liu, W.; Venugopal, S.; Majid, S.; Ahn, I.S.; Diamante, G.; Hong, J.; Yang, X.; Chandler, S.H. Single-Cell RNA-Seq Analysis of the Brainstem of Mutant SOD1 Mice Reveals Perturbed Cell Types and Pathways of Amyotrophic Lateral Sclerosis. Neurobiol. Dis. 2020, 141. [CrossRef] [PubMed]

82. Krasemann, S.; Madore, C.; Cialic, R.; Baufeld, C.; Calcagno, N.; El Fatimy, R.; Beckers, L.; O'Loughlin, E.; Xu, Y.; Fanek, Z.; et al. The TREM2-APOE Pathway Drives the Transcriptional Phenotype of Dysfunctional Microglia in Neurodegenerative Diseases. Immunity 2017, 47, 566-581.e9. [CrossRef] [PubMed]

83. Noristani, H.N.; Sabourin, J.C.; Gerber, Y.N.; Teigell, M.; Sommacal, A.; Vivanco, M.D.M.; Weber, M.; Perrin, F.E. Brca1 Is Expressed in Human Microglia and Is Dysregulated in Human and Animal Model of ALS. Mol. Neurodegener. 2015, 10. [CrossRef]

84. Renton, A.E.; Chiò, A.; Traynor, B.J. State of Play in Amyotrophic Lateral Sclerosis Genetics. Nat. Neurosci. 2014, 17, 17-23. [CrossRef]

85. Taylor, J.P.; Brown, R.H.; Cleveland, D.W. Decoding ALS: From Genes to Mechanism. Nature 2016, 539, 197-206. [CrossRef]

86. Lutz, C. Mouse Models of ALS: Past, Present and Future. Brain Res. 2018, 1693, 1-10. [CrossRef] [PubMed]

87. DeJesus-Hernandez, M.; Mackenzie, I.R.; Boeve, B.F.; Boxer, A.L.; Baker, M.; Rutherford, N.J.; Nicholson, A.M.; Finch, N.C.A.; Flynn, H.; Adamson, J.; et al. Expanded GGGGCC Hexanucleotide Repeat in Noncoding Region of C9ORF72 Causes Chromosome 9p-Linked FTD and ALS. Neuron 2011, 72, 245-256. [CrossRef] [PubMed]

88. Chen, H.; Kankel, M.W.; Su, S.C.; Han, S.W.S.; Ofengeim, D. Exploring the Genetics and Non-Cell Autonomous Mechanisms Underlying ALS/FTLD. Cell Death Differ. 2018, 25, 646-660. [CrossRef]

89. O'Rourke, J.G.; Bogdanik, L.; Yáñez, A.; Lall, D.; Wolf, A.J.; Muhammad, A.K.M.G.; Ho, R.; Carmona, S.; Vit, J.P.; Zarrow, J.; et al. C9orf72 Is Required for Proper Macrophage and Microglial Function in Mice. Science 2016, 351, 1324-1329. [CrossRef]

90. Chew, J.; Gendron, T.F.; Prudencio, M.; Sasaguri, H.; Zhang, Y.J.; Castanedes-Casey, M.; Lee, C.W.; Jansen-West, K.; Kurti, A.; Murray, M.E.; et al. C9ORF72 Repeat Expansions in Mice Cause TDP-43 Pathology, Neuronal Loss, and Behavioral Deficits. Science 2015, 348, 1151-1154. [CrossRef]

91. O’Rourke, J.G.; Bogdanik, L.; Muhammad, A.K.M.G.; Gendron, T.F.; Kim, K.J.; Austin, A.; Cady, J.; Liu, E.Y.; Zarrow, J.; Grant, S.; et al. C9orf72 BAC Transgenic Mice Display Typical Pathologic Features of ALS/FTD. Neuron 2015, 88, 892-901. [CrossRef]

92. Peters, O.M.; Cabrera, G.T.; Tran, H.; Gendron, T.F.; McKeon, J.E.; Metterville, J.; Weiss, A.; Wightman, N.; Salameh, J.; Kim, J.; et al. Human C9ORF72 Hexanucleotide Expansion Reproduces RNA Foci and Dipeptide Repeat Proteins but Not Neurodegeneration in BAC Transgenic Mice. Neuron 2015, 88, 902-909. [CrossRef]

93. Liu, Y.; Pattamatta, A.; Zu, T.; Reid, T.; Bardhi, O.; Borchelt, D.R.; Yachnis, A.T.; Ranum, L.P.W. C9orf72 BAC Mouse Model with Motor Deficits and Neurodegenerative Features of ALS/FTD. Neuron 2016, 90, 521-534. [CrossRef] 
94. Batra, R.; Lee, C.W. Mouse Models of C9orf72 Hexanucleotide Repeat Expansion in Amyotrophic Lateral Sclerosis/ Frontotemporal Dementia. Front. Cell. Neurosci. 2017, 11. [CrossRef] [PubMed]

95. Langseth, A.J.; Kim, J.; Ugolino, J.E.; Shah, Y.; Hwang, H.Y.; Wang, J.; Bergles, D.E.; Brown, S.P. Cell-Type Specific Differences in Promoter Activity of the ALS-Linked C9orf72 Mouse Ortholog. Sci. Rep. 2017, 7. [CrossRef]

96. Nicholson, A.M.; Zhou, X.; Perkerson, R.B.; Parsons, T.M.; Chew, J.; Brooks, M.; DeJesus-Hernandez, M.; Finch, N.C.A.; Matchett, B.J.; Kurti, A.; et al. Loss of Tmem106b Is Unable to Ameliorate Frontotemporal Dementia-like Phenotypes in an AAV Mouse Model of C9ORF72-Repeat Induced Toxicity. Acta Neuropathol. Commun. 2018, 6, 42. [CrossRef] [PubMed]

97. Zhang, Y.J.; Gendron, T.F.; Grima, J.C.; Sasaguri, H.; Jansen-West, K.; Xu, Y.F.; Katzman, R.B.; Gass, J.; Murray, M.E.; Shinohara, M.; et al. C9ORF72 Poly(GA) Aggregates Sequester and Impair HR23 and Nucleocytoplasmic Transport Proteins. Nat. Neurosci. 2016, 19, 668-677. [CrossRef] [PubMed]

98. Lagier-Tourenne, C.; Baughn, M.; Rigo, F.; Sun, S.; Liu, P.; Li, H.R.; Jiang, J.; Watt, A.T.; Chun, S.; Katz, M.; et al. Targeted Degradation of Sense and Antisense C9orf72 RNA Foci as Therapy for ALS and Frontotemporal Degeneration. Proc. Natl. Acad. Sci. USA 2013, 110. [CrossRef]

99. Benajiba, L.; Le Ber, I.; Camuzat, A.; Lacoste, M.; Thomas-Anterion, C.; Couratier, P.; Legallic, S.; Salachas, F.; Hannequin, D.; Decousus, M.; et al. TARDBP Mutations in Motoneuron Disease with Frontotemporal Lobar Degeneration. Ann. Neurol. 2009, 65, 470-473. [CrossRef]

100. Lee, E.B.; Lee, V.M.Y.; Trojanowski, J.Q. Gains or Losses: Molecular Mechanisms of TDP43-Mediated Neurodegeneration. Nat. Rev. Neurosci. 2012, 13, 38-50. [CrossRef]

101. Neumann, M.; Sampathu, D.M.; Kwong, L.K.; Truax, A.C.; Micsenyi, M.C.; Chou, T.T.; Bruce, J.; Schuck, T.; Grossman, M.; Clark, C.M.; et al. Ubiquitinated TDP-43 in Frontotemporal Lobar Degeneration and Amyotrophic Lateral Sclerosis. Science 2006, 314, 130-133. [CrossRef] [PubMed]

102. Zhang, H.; Tan, C.F.; Mori, F.; Tanji, K.; Kakita, A.; Takahashi, H.; Wakabayashi, K. TDP-43-Immunoreactive Neuronal and Glial Inclusions in the Neostriatum in Amyotrophic Lateral Sclerosis with and without Dementia. Acta Neuropathol. 2008, 115, 115-122. [CrossRef] [PubMed]

103. McGoldrick, P.; Joyce, P.I.; Fisher, E.M.C.; Greensmith, L. Rodent Models of Amyotrophic Lateral Sclerosis. Biochim. Biophys. Acta Mol. Basis Dis. 2013, 1832, 1421-1436. [CrossRef] [PubMed]

104. Dutta, K.; Patel, P.; Rahimian, R.; Phaneuf, D.; Julien, J.P. Withania Somnifera Reverses Transactive Response DNA Binding Protein 43 Proteinopathy in a Mouse Model of Amyotrophic Lateral Sclerosis/Frontotemporal Lobar Degeneration. Neurotherapeutics 2017, 14, 447-462. [CrossRef]

105. Correia, A.S.; Patel, P.; Dutta, K.; Julien, J.P. Inflammation Induces TDP-43 Mislocalization and Aggregation. PLoS ONE 2015, 10. [CrossRef] [PubMed]

106. Falconer, D.S. Wobbler (Wr). Mouse News Lett. 1956, 15, 22.

107. Schmitt-John, T.; Drepper, C.; Mußmann, A.; Hahn, P.; Kuhlmann, M.; Thiel, C.; Hafner, M.; Lengeling, A.; Heimann, P.; Jones, J.M.; et al. Mutation of Vps54 Causes Motor Neuron Disease and Defective Spermiogenesis in the Wobbler Mouse. Nat. Genet. 2005, 37, 1213-1215. [CrossRef]

108. Boillée, S.; Peschanski, M.; Junier, M.P. The Wobbler Mouse: A Neurodegeneration Jigsaw Puzzle. Mol. Neurobiol. 2003, 28, 65-106. [CrossRef]

109. Moser, J.M.; Bigini, P.; Schmitt-John, T. The Wobbler Mouse, an ALS Animal Model. Mol. Genet. Genom. 2013, 288, 207-229. [CrossRef]

110. Cipollina, G.; Serej, A.D.; Di Nolfi, G.; Gazzano, A.; Marsala, A.; Spatafora, M.G.; Peviani, M. Heterogeneity of Neuroinflammatory Responses in Amyotrophic Lateral Sclerosis: A Challenge or an Opportunity? Int. J. Mol. Sci. 2020, 21, 7923. [CrossRef] 